IZA DP No. 4684

Work Out or Out of Work: The Labor Market Return to Physical Fitness and Leisure Sport Activities

Dan-Olof Rooth

January 2010 


\title{
Work Out or Out of Work: The Labor Market Return to Physical Fitness and Leisure Sport Activities
}

\author{
Dan-Olof Rooth \\ Linnaeus University, \\ CReAM and IZA
}

\section{Discussion Paper No. 4684 \\ January 2010}

\author{
IZA \\ P.O. Box 7240 \\ 53072 Bonn \\ Germany \\ Phone: +49-228-3894-0 \\ Fax: +49-228-3894-180 \\ E-mail: iza@iza.org
}

Any opinions expressed here are those of the author(s) and not those of IZA. Research published in this series may include views on policy, but the institute itself takes no institutional policy positions.

The Institute for the Study of Labor (IZA) in Bonn is a local and virtual international research center and a place of communication between science, politics and business. IZA is an independent nonprofit organization supported by Deutsche Post Foundation. The center is associated with the University of Bonn and offers a stimulating research environment through its international network, workshops and conferences, data service, project support, research visits and doctoral program. IZA engages in (i) original and internationally competitive research in all fields of labor economics, (ii) development of policy concepts, and (iii) dissemination of research results and concepts to the interested public.

IZA Discussion Papers often represent preliminary work and are circulated to encourage discussion. Citation of such a paper should account for its provisional character. A revised version may be available directly from the author. 


\section{ABSTRACT}

\section{Work Out or Out of Work: The Labor Market Return to Physical Fitness and Leisure Sport Activities}

This study is the first to present evidence of the return to leisure sports in the job hiring process by sending fictitious applications to real job openings in the Swedish labor market. In the field experiment job applicants were randomly given different information about their type and level of leisure sport being engaged in. Applications which signal sport skills have a significantly higher callback rate of about two percentage points for men, and this effect is about twice as large in physically demanding occupations. This indicates a health-productivity interpretation of the results. However, the result is mainly driven by the return to sports as soccer and golf, and not at all by more fitness related sports as running and swimming, which is indicative of alternative explanations for the labor market sports premium. One possible explanation emerges when analyzing register data on adult earnings and physical fitness when enlisting at age 18. The fitness premium, net of unobservable family variables, is in the order of 4-5 percent, but diminishes to 1 percent when controlling for non-cognitive skills. Hence, these results indicate that being engaged in leisure sports signals having important social skills.

JEL Classification: J21, J64, J71

Keywords: leisure sports, physical fitness, cardiovascular fitness, correspondence testing, earnings

Corresponding author:

Dan-Olof Rooth

Linnaeus School of Business and Economics

Linnaeus University

Kalmar Nyckel

SE-39182 Kalmar

Sweden

E-mail: Dan-Olof.Rooth@Inu.se

\footnotetext{
* I thank Jens Agerström, Magnus Carlsson and Rickard Carlsson and seminar participants at SOFI, Stockholm University, for valuable comments. A research grant from the social sciences faculty at Linnaeus University and another from the Swedish Council for Working Life and Social Research are gratefully acknowledged.
} 


\section{Introduction}

According to the canonical model, earnings are determined by human capital, that is, individual capabilities that contribute to production. Labor economists have almost exclusively focused on education and cognitive ability in constituting such capabilities, see Card (1999) for a survey. However, recent advances show that also non-cognitive psychological traits, such as personality and self-discipline, are just as important determinant of wages as cognitive skills, and should be included in the earnings equation. ${ }^{1}$ Increasing attention has also been given to non-cognitive physical traits previously expected to be unrelated to productivity, such as beauty, height and weight, and how employers value these attributes. ${ }^{2}$

In order to be able to decrease earning inequalities in society learning what additional factors that constitute the full vector of capabilities that enhance individual earnings is an important task. Hence, in this study yet another physical attribute, that is, physical fitness and its relation to earnings is explored. In addition we study if recruiters value job applicants being engaged in leisure sport activities of various sorts and intensities. The economic value of being physically fit and/or engaging in leisure sport activities is also an important research topic in its own right since it relates to the increase in obesity in Western societies and the associated decrease in public health. Also, governments in Sweden and elsewhere subsidize leisure sport activities to a great extent (Lechner, 2009), emphasizing the importance these governments place on good health, not only for the elderly, but also for children and working-age adults.

Although much attention has been directed towards the association between (usually bad) health and (bad) labor market outcomes little is known about the leisure sports/physical fitness premium ${ }^{3}$ in the labor market. ${ }^{4}$ The few studies that set out to

\footnotetext{
${ }^{1}$ See Bowles, Gintis and Osborne (2001), Borghans et al (2008) and Heckman and Rubinstein (2001) for research on the importance of psychological traits in the labor market.

${ }^{2}$ See e.g., Hamermesh and Biddle (1994), Case and Paxson (2008) and Rooth (2009) for research on the importance of beauty, height and weight, respectively, on labor market outcomes.

${ }^{3}$ Both these specific concepts can be captured under the more general term sports premium being used in this article, capturing also other concepts as social network effects arising from sports participation.

${ }^{4}$ See Currie and Mandrian (1999) for a review of studies on health and labor market outcomes.
} 
estimate a "sports" premium in the labor market have used two different approaches. A number of US studies have analyzed the association between participating in high school or college sports and wages, see e.g., Ewing (2007). The only study which measures the level of sports participation is Lechner (2009) who studies if being more physically active, which is self-reported, is associated with higher earnings. Overall, these studies find a positive association between sports (participation) and earnings.

Lechner proposes three channels through which an association between sports/physical fitness and earnings/wages could exist. First, a higher level of physical fitness could have a direct productivity link to wages through improved health - more fit/healthier individuals work longer days, at higher intensities and have fever sick days. ${ }^{5}$ Second, unobserved variables could cause both sports participation/physical fitness and high wages. For instance, those participating in sports might have a greater social network being relevant for the labor market, especially those engaged in team sports. Finally, participating in sports might signal to employers that individuals enjoy good health and are motivated and can therefore be expected to perform well on the job. ${ }^{6}$ However, empirically it is very difficult to disentangle these channels, and in addition, those participating in sports might be a selective group in many respects rendering estimates of the "sports" premium even more difficult.

In this study we make use of two quite unique data sets to learn more about the "sports" premium. First, we use data on individual physical fitness when enlisting at age 18 and adult earnings. To the extent that having a greater oxygen uptake is caused by participating in sports, this analysis captures some notion of a sports premium in earnings. In fact, according to expertise, individuals with higher measures of physical fitness can be expected to have reached this by exercising more intense, see also Rashad (2007). ${ }^{7}$ Hence, for this study we ask whether an outcome of being more active in sports,

\footnotetext{
5 This explanation might be relevant in the Swedish context since sickness spells shorter than 14 days at a time are borne exclusively by the employer.

${ }^{6}$ Similar channels are proposed by Cawley (2004) for the link between obesity and wages.

${ }^{7}$ Jan Henriksson, a professor in physiology at Karolinska Institutet, states that although biological variation can have some impact, a higher level of physical fitness, as measured by maximum Watts/kilogram bodyweight, have by far the highest correlation with training intensity, and, to a somewhat lesser degree, also with training hours. Hence, this fitness measure mostly captures to what extent individuals are engaged
} 
that is, having a higher level of physical fitness, is associated with higher earnings. The enlistment data also include a number of control variables, that is, a measure of cognitive ability, non-cognitive ability and other health related variables as BMI and height, rendering it possible to investigate through which mechanism this fitness premium arise.

Second, while associations are of interest we would prefer to discuss results based on exogenous variation in sports participation (or level of fitness). Hence, in order to account for differences in productive characteristics being correlated with sports we have conducted a field experiment sending fictitious job applications to real job openings randomly including information on different types of leisure sport skills. ${ }^{8}$ This kind of field experiment ${ }^{9}$ has specifically been designed to test for discrimination in recruitment, but has recently been developed to also study how personal attributes affect the callback for a job interview. ${ }^{10}$ The correspondence testing methodology, in this particular setting, implies that the researcher sends job applications to advertised job openings with the only difference between applications being the information given in the letter. For example, some job applications include no information about sport activities while others include information that the person is engaged in a team (soccer or basketball) or an individual sport (running, swimming, tennis or golf) on a recreational or competitive level (level of intensity). The return to different leisure sports is quantified by the difference in the probability of callbacks for interview between applications signaling and not signaling sport participation.

The results for the register data, correcting for the family context using sibling (brothers) fixed effects when estimating the physical fitness-earnings association, show

(intensity and/or duration) in physically demanding sports, that is, sports in which oxygen consumption is important.

${ }^{8}$ These data have been collected within a discrimination project that started in 2006, which measures the extent of ethnic and gender discrimination in hiring by sending fictitious job applications. In this project over 7,000 jobs have been applied to, sending over 20,000 job applications.

${ }^{9}$ See Riach and Rich (2002) for a summary of the situation test experiments that have been conducted measuring ethnic and gender discrimination in hiring.

${ }^{10}$ Bertrand and Mullainathan (2004) also use variation in application information to analyze how treatment varies across application attributes. However, although randomly attaching extracurricular activities such as volunteering and honors to resumes they did not attach sport activities in a systematic manner. 
that those with a one standard deviation higher level of fitness have four percent higher earnings. This association is not affected by including height or BMI into the regression but diminishes by twenty-two percent when controlling for cognitive ability. When controlling for non-cognitive ability the fitness-earnings association is lowered by almost two-thirds. Hence, while fitness still being an important determinant of earnings, most of its association with earnings is linked to that those with greater physical fitness also have greater non-cognitive skills. The results for the field experiment yield a similar result. We do not find a general sports premium in hiring, that is, across occupations and sports, as one would expect if being engaged in leisure sports were merely a signal of better health. However, when grouping the occupations the results indicate a health-productivity explanation for the sports premium in occupations being classified as physically demanding. The leisure sports being valued the most by recruiters are soccer and golf, not the more fitness related sports of running and swimming. Hence, since soccer and golf can be associated with as being very social sports recruiters might be valuing this dimension. $^{11}$

The remainder of this article is outlined as follows. Section 2 presents previous studies in the literature related to sport skills. Section 3 presents the data and the analysis of the return to sport skills when using the register/enlistment data, while Section 4 has the same outline employing the field experimental data. Section 5 concludes.

\section{Literature review}

The number of studies that relate to ours when using a broad definition of a "sports" premium in earnings include studies on the obesity penalty, the height and beauty premium and the premium to non-cognitive psychological traits. ${ }^{12}$ Further, it is well documented in the medical and epidemiological literature that there is a positive effect of

\footnotetext{
${ }^{11}$ Although golf is an individual sport it is often exercised together with friends and can in this dimension be classified as a social sport.

${ }^{12}$ Although the literature on the return to sports in the regular labor market is quite infant, the field of sport economics is not, dating back at least to the work of Rottenberg (1956), see also Sloane (2006) and Kahn (2000). We refrain from discussing this voluminous literature of professional sport economics due to space limitations.
} 
sports activity on physical health, see Lechner (2009) and the references therein. Several studies also show that those who participate in sports is a selective group in dimensions as education, earnings and social status, and gender, see Lechner (2009). ${ }^{13}$

The first studies that set out to estimate a "sports" premium in earnings where those that analyzed the effects of participating in US high school or college sports on future labor market outcomes. Using various econometric methods to overcome the problem of self-selection into high school sports, this literature finds a positive association between participation in such sports and labor market outcomes, see Barron, Ewing and Waddell (2000), Ewing (1998, 2007), and Long and Caudill (2001).

More related to the present study is Lechner (2009) who was the first to study the effects of variation in the level of individual leisure sports participation on long-term labor market outcomes using the years 1984 to 2006 for the German Socio-Economic Panel study (GSOEP). Proposing a solution for the econometric problem that individuals choose their level of sports activities, the study shows that sports activities have sizeable positive long-term labor market effects on earnings and wages, similar in size to one additional year of schooling. Also, increased health and improved well-being in general seem to be relevant channels to generate these gains in earnings.

One obvious channel for a sports premium to occur is through its relation to good health. Studies that set out to estimate a labor market return to health have used somewhat different approaches ranging from using a self-reported measure of individual overall health conditions to using clinical evaluations of individual's health status. Currie and Madrian (1999) state that the overall impression from this literature is that the associations between health status and labor market outcomes are mostly positive, but not very strong. In the following we will only be discussing the results from the literature on the obesity penalty. Due to its close similarity to physical fitness and that it primarily focus on working-age individuals it can provide a benchmark for what to expect for the fitness premium. ${ }^{14}$

\footnotetext{
${ }^{13}$ See also, Gratton and Taylor (2000) and Farrel and Shields (2002).

14 Hence, studies that analyze, for example, asthma or diabetes and their association to labor market outcomes are not discussed since they are less associated with being physically fit, see also Ruhm (2007).
} 
Cawley (2004) uses the National Longitudinal Survey of Youths (NLSY) to estimate an obesity effect. ${ }^{15}$ Previous studies have used multiple reports of body weight and sibling differences in an attempt to cancel out the effects of shared family environment and genetics. Cawley takes the analysis one step further by also instrumenting mother's weight with child's weight and ends up with an obesity wage penalty that is sizable and statistically significant for women, while the results for males are more mixed. Rooth (2009) presents evidence of differential treatment in the hiring of obese individuals in the Swedish labor market sending fictitious applications to real job openings. The applications were sent in pairs, where one facial photo of an otherwise identical applicant was manipulated to show the individual as obese. Applications sent with the weightmanipulated photo had a significantly lower callback response for an interview being six percentage points lower for men and eight percentage points lower for women. This differential treatment varies a lot by occupation and is large in sales occupations, but also in restaurant work. Also, there are indications that the results for men are being driven by attractiveness, while the results for women are driven by obesity. Lundborg, Nystedt and Rooth (2009a) analyze the association between BMI and earnings using enlistment data for siblings and find that non-cognitive skills explain about half of the obesity penalty, while cognitive skills explain around twenty-five percent.

Other physical attributes than obesity, as height and beauty, have also proven to be associated with labor market success, and these attributes can, as we will show, be expected to be at least somewhat related to being physically fit or being active in leisure sports. In the following we mainly discuss those studies that analyses how sensitive these associations are when including additional control variables, mainly focusing on cognitive and non-cognitive skill variables.

Using the data in this study we find that physical fitness is correlated with height. Hence, the association between physical fitness/leisure sports and earnings might to some extent be driven by a height premium. At least three recent studies have set out to explain the height premium in earnings using register data with additional information on

\footnotetext{
${ }^{15}$ See for example also the studies by Register and Williams (1990), Averett and Korenman (1996), and Pagan and Davlia (1997).
} 
individual cognitive skills, non-cognitive skills. ${ }^{16}$ In their analysis of data from the UK and US (National Child Development Study, NCDS and National Longitudinal Survey of Youth, NLSY, respectively), Persico et al. (2004) find that teen height essentially explains the full association between adult height and hourly wages, among white men. In addition, they find that childhood cognitive test scores do not affect the estimated height premium, but rather that the link between teen height and later life earnings runs via participation in activities that build social skills and social capital during adolescence. Case and Paxson (2008) use the same data and find that cognitive ability measured in childhood and youth explains 30-50 percent of the height premium. Lundborg, Nystedt and Rooth (2009b) find that both cognitive and non-cognitive skills explain about one third of the height premium, which corresponds fairly well to the results obtained by Persico et al (2004) and Case and Paxson (2008). However, they also find that a measure of physical strength (not fitness) explains about 80 percent of the height premium.

There also exists some evidence that physically fit individuals are more attractive. In the study by Fink et al. (2007) rated attractiveness was found to be correlated with the rated subjects' physical strength, and in an experimental setting Mobius and Rosenblat (2006) find that attractive persons receive higher wages because they are perceived as more able, conditional on productive skills. Hence, it is possible that the sports premium to some extent captures an attractiveness premium. The study by Hamermesh and Biddle (1994) estimates a premium of having average looks relative to being unattractive of about 5-10 percent on wages in the US, while Harper (2000) estimates a similar model for the United Kingdom, finding a corresponding premium of 11 and 15 percent for women and men, respectively. In both studies the premium to being attractive, relative to those with average looks, is less pronounced and in the study by Harper also statistically insignificant.

The association between physical attributes and labor market outcomes seems to some extent be attributed to cognitive skills, but even more so to non-cognitive skills. There also exists a gender difference in that men and women are evaluated differently when obese. Hence, also the sports premium may vary by gender.

\footnotetext{
16 A number of other studies have examined the impact of stature on labor market outcomes, see for example Hamermesh and Biddle (1994), Harper (2000), and Behrman and Rosenzweig (2001).
} 
Finally, there is also a fairly new, but already quite extensive, literature analyzing the connection between non-cognitive skills in terms of personality traits and labor market outcomes. For instance, Heckman et al. (2006) show that non-cognitive skills are important predictors of wages, schooling, and a range of risky behaviors, but that noncognitive skills also have independent effect on earnings over and above their effect on schooling. For wages, they find that non-cognitive skills matter more than cognitive skills. Similar results for education are obtained in Duckworth and Seligman (2005), who find that measures of self-discipline are stronger predictors of academic performance than cognitive skills. Other examples of the importance of non-cognitive skills are Blanden et al. (2007), where non-cognitive skills are important determinants of the intergenerational transmission of income, and Fenstein (2000), where measures of self-esteem are found to be important predictors of earnings. Borghans et al (2008) explore in depth the connection between personality traits and labor market outcomes finding that those who score high on the Big Five category extroversion receive higher wages. Lindqvist and Vestman (2009) also analyze the labor market returns to cognitive and non-cognitive skills using the same high-quality data on cognitive and non-cognitive skills from the Swedish military enlistment records as the present study and show that both types of skills are of about equal importance for earnings.

To conclude, being physically fit or being active in leisure sports might be correlated with a number of personal characteristics such as social skills, attraction, cognitive ability and health, giving rise to empirical concerns as to what the "sports" premium constitute. In the reminder we will try to remedy some of these concerns by employing a data set rich on important control variables as well as experimental data on hiring practices in the real world.

\section{Register data on earnings and physical fitness}

\subsection{Enlistment data}

This empirical analysis is based on a data set constructed by integrating registers from Statistics Sweden (SCB) and the Swedish National Service Administration. The latter contains information on every individual living in Sweden in the year 1999 who enlisted 
for the military between 1984 and 1997. ${ }^{17}$ Our study population consists of all males who were 28-38 years old in 2003, who enlisted for the military, and for whom there is full information on relevant variables. Enlisting for the military is carried out during a twoday procedure and is mandatory for all male Swedish citizens the year they turn 18. Only persons with severe handicap, institutionalized persons (both due to mental disorders or being in prison), or persons living abroad are exempted from enlisting. ${ }^{18}$ It should also be noted that a refusal to enlist results in fines, and eventually in imprisonment. In order to avoid any confounding influence of ethnic discrimination, we restrict our analyses to native Swedish males, i.e., those born in Sweden to Swedish-born parents. ${ }^{19}$ Given these restrictions, our study population covers about 92 percent of the total native male Swedish population in the relevant cohorts.

Our base sample consists of 468,312 individuals. Out of these, 446,930 individuals or 96 percent, had positive annual earnings in 2003, which is the sample that we use in our analyses. However, in the main parts of the analysis we focus on variation between siblings, which reduces the sample being analyzed to 144,671 individuals. Since the enlistment variables are measured by military personnel, and earnings by tax authorities, our results are not influenced by any reporting bias, which often plagues survey data.

Our measure of annual earnings includes income from work, self-employed income and social insurance benefits such as sickness benefits, child allowance and parental benefits for the year 2003 and is taken from the tax records. A sensitivity analysis where only income from work and self-employed income is included in the measure of earnings, shows that the inclusion of social insurance benefits does not affect our results. ${ }^{20}$

In order to correctly identify a physical fitness premium, care must be taken in choosing which variables to include in the earnings equation. In an influential article,

${ }^{17}$ The individuals had to live in Sweden during 1999 since the enlistment information was initially collected for the 1999 population data.

${ }^{18}$ Since the persons in our sample enlisted during the years 1984-1997, and since earnings are followed up in 2003, this implies that we lose a small number of people due to death and emigration. There is no information available on why a particular individual did not enlist.

${ }^{19}$ Moreover, non-native ethnic groups have a much lower participation rate for enlisting since only about fifty percent (or less) are Swedish citizens, making selective participation an issue for these groups.

${ }^{20}$ These results are available upon request. 
Neal and Johnson (1996) argue that only exogenous variables, i.e., variables determined before labor market entry, should be included in the model specification. Variables commonly used to control for worker productivity, such as occupation and postsecondary education, are in this respect likely to be endogenous. We argue in a similar vein that controlling for such variables would hide part of the fitness premium if more fit individuals sort themselves into certain educations or jobs. Hence, to avoid such selection problems we use a measure of physical fitness taken before entering the labor market, that is, at age 18 when enlisting.

Although preferable in this context, we need to address the problems involved when physical fitness is measured at least ten years ahead of earnings. Contrary to for instance height, physical fitness is not permanent but changes if physical activity changes. Hence, to the extent that there is no perfect correlation of physical fitness measured at different ages we will reach an estimate that includes some amount of noise and is therefore downward biased. Interestingly then, in the empirical analysis we do find a statistically significant and sizable return to physical fitness proving that the correlation in physical fitness over time is not zero. Hence, the estimate could be seen as a lower bound of the earnings-fitness association.

In order to empirically measure physical fitness, we make use of a test score on physical work capacity and body weight. ${ }^{21}$ Physical work capacity is measured as the maximum resistance attained in Watts when riding on a stationary bike during a specific time period (around 5-10 minutes). ${ }^{22}$ This measure is closely related to maximum oxygen consumption $\left(\mathrm{VO} 2_{\max }\right)$, which has been labeled as the single best measure of cardiovascular capacity and maximal aerobic power (Hyde and Gengenbach 2007). ${ }^{23}$

\footnotetext{
${ }^{21}$ In the appendix we also include results when using a measure of handgrip strength, which is measured as the maximum pressure exerted by one hand squeezing a bar. Grip strength is a common method for assessing overall muscle strength (Gale et al. 2007).

${ }^{22}$ In the cycle ergonometry test the subject was instructed to maintain pedal cadence between 60 and 70 $\mathrm{rpm}$. The test was initiated with $5 \mathrm{~min}$ of submaximal exercise at work rates of 75 to $175 \mathrm{~W}$, depending on expected fitness. The work rate was then continuously increased by $25 \mathrm{~W} / \mathrm{min}$ until volitional exhaustion. In the end the final work rate $\left(\mathrm{W}_{\max }\right)$ was recorded.

${ }^{23}$ Directly measuring maximum oxygen consumption is costly and time-consuming, meaning that indirect measures are often preferred when large numbers of people are being tested.
} 
Since individual needs for energy vary with body size, maximum oxygen consumption is often expressed relative to body weight, which is the measure we will use for physical fitness, that is, maximum Watts attained on the stationary bike divided by body weight.

Cognitive skill is measured using a test similar in style to the AFQT in the US. The name of the test is Enlistment Battery 80 and it includes four separate tests, Instructions, Synonyms, Metal Folding, and Technical Comprehension. The cognitive skill variable used in the analysis is a standardized version of the composite cognitive measure calculated by the military enlistment service, which ranges from 1 to $9 .^{24}$

Non-cognitive skills are measured through interviews carried out by certified psychologists. ${ }^{25}$ The interview is intended to contain assessments of psychological stability and endurance, capability of taking initiative, responsibility, and social competence. The ultimate purpose of the interview is to evaluate the conscript's ability to perform military service and to function in a war situation. This evaluation results in a composite enlistment score of non-cognitive skills, ranging from 1 to 9 , which is being standardized in the analyses. ${ }^{26}$

In the analysis we also control for age fixed effects, which picks up any non-linearity in the age profile for earnings but also any changes in the measurement of the enlistment variables from year to year. Since 99 percent of the conscripts enlisted at age 18 or 19 (86 and 13 percent, respectively) the age fixed effects also pick up anything specific for the year the conscript enlisted. It is therefore reassuring that the results are insensitive to if only age, age-when-enlisting, or both are included in the analysis. In addition we control for height and BMI to control for other potential health effects being associated with physical fitness.

\footnotetext{
${ }^{24}$ The general intelligence factor, G, is the variable used in this study. For more information about the G factor, see Carroll (1993). The separate tests and the composite measure have a correlation of above 0.9.

${ }^{25}$ Exact details of this part of the enlistment process are not publically revealed and we are merely referred to information on the intentions of the assessment procedure. It should be noted that our measure of noncognitive ability is a strong predictor of earnings, independently of cognitive skills.

${ }^{26}$ Though the original purpose of the non-cognitive skill measure used here is to evaluate peoples' suitability to serve in a war situation, it seems reasonable to assume that the character traits valued by the military psychologists (psychological stability and endurance, capability of taking initiatives, responsibility and social competence etc.) may also be appreciated and rewarded in the labor market.
} 
It should be noted that almost all people that enlisted during our study period also completed military service. For the vast majority of the study sample, the enlistment test results did not affect the decision as to whether they will have to do military service or not. Instead, the tests merely influence the individual's placement in the army, meaning that poorer results will typically lead to a less qualified and meriting placement. From this respect the incentives to deliberately underperform on the tests are limited. We have performed some sensitivity tests, that is, excluding those with very low and high scores on the cognitive test, without finding any indications of "enlistment fakers" affecting our results.

The distributions for our key variables (log) earnings and physical fitness for the total population are illustrated in Figure 1. The figure shows that earnings rise with physical fitness across the entire distribution.

\section{*** Figure 1 about here ***}

Descriptive statistics of the key variables used in the empirical analysis, i.e. earnings, physical fitness and the different enlistment test scores, etc., are given in Table 1 for those below and above median physical fitness. The main picture that emerges is that there are differences between more or less fit men in all dimensions, but that these differences in general are small.

In section 2 we introduced two personal characteristics that potentially could explain the physical fitness premium; cognitive skills and non-cognitive skills. By including them one by one, as well as together, in the earnings equation, we will analyze to what extent that is the case. Equation 1 shows the model when estimating the sibling fixed effect model:

$$
\text { 1) } \quad \log \text { Earnings }_{i j}=a+b^{*} \text { Fitness }_{i j}+c^{*} X_{i j}+f_{j}+e_{i j}
$$

where $i$ is index for individual and $j$ for family, Fitness is a standardized measure of individual $\mathrm{W}_{\max } / \mathrm{kg}, X$ is a vector of individual characteristics measured when enlisting, and $f_{j}$ represents family fixed effects capturing family characteristics common to all 
siblings (brothers) within the same family. The model is then altered by including different variables into $X$. Identification of the coefficient $b$ thus relies upon sibling variation in fitness at age 18. In this specification, our estimate of $b$ should not be subject to bias due to any confounding influence from unobserved family-level unobservables that are also associated with earnings.

\subsection{Results - explaining the earnings premium to physical fitness}

We start out with the full set of 446,930 observations, including only physical fitness and age into the earnings regression. As shown in Model $\mathrm{A}$ in the first row of Table 2, a one standard deviation higher level of fitness is associated with seven percent higher earnings. ${ }^{27}$ This estimate may be biased if there are important unobserved family-level characteristics that are associated with both earnings and the measure of physical fitness. In order to control for any such family-specific unobservable factors, we instead use the sample of 144,671 brothers. ${ }^{28}$ First of all, this smaller data do seem representative of the larger total data since regressing earnings on physical fitness and age without sibling fixed effects yields a fitness premium for this sibling sample that exactly corresponds to the one for the total population data, (compare Model A and B). The fitness premium is lowered only somewhat, to six percent, when including controls for parental years of schooling and income (Model C). Hence, these family variables are not very important in explaining the fitness premium in earnings. However, when introducing sibling fixed effects the fitness premium decreases to four percent (Model D), suggesting that factors operating at the family-level explain almost half of the crude fitness premium. Adding BMI and height (Model E) actually increases the fitness premium somewhat, while cognitive skills (Model F) lowers it by a similar amount. Interestingly, non-cognitive skills (Model G) is the variable being most associated with physical fitness. A one standard deviation increase in physical fitness is in this model only associated with a 1.7

\footnotetext{
${ }^{27}$ See also Table A2 in the appendix for the results using the total population data.

${ }^{28}$ It could potentially be important to control also for birth order effects, and especially for being first born. However, the correlation of these variables with the physical fitness is found to be essentially non-existent and had therefore no impact on the fitness earnings premium. We therefore decided not to include this variable in the analysis.
} 
percent increase in earnings. Including all these variables at the same time does not do a better job in reducing the fitness premium than non-cognitive skills do alone. ${ }^{29}$

\section{$* * *$ Table $2 * * *$}

Turning instead to years of schooling as our outcome measure very similar results are obtained, see the second row of Table 2, with the exception that cognitive skills now are more important than it was for earnings in reducing the fitness-earnings association. The fitness premium when using sibling fixed effects is reduced by approximately one third when cognitive skills are controlled for (compare Model D and F) and by a similar amount when non-cognitive skills are controlled for (compare Model D and G).

In the appendix, see Table A3, the results instead using a measure of physical strength, that is, handgrip strength, is given. Although this measure is less associated with earnings than physical fitness the results are qualitatively similar.

We conclude this section with that the fitness earnings premium, net of unobserved family variables, is at least four percent when increasing the fitness level by one standard deviation. This premium amounts being similar to the earnings premium to one additional year of schooling, but is heavily (downwards) influenced by the inclusion of noncognitive skills into the model. Next, we turn to the data and results for the field experiment.

\footnotetext{
${ }^{29}$ Although potentially being endogenous we have also elaborated with including occupation and years of schooling fixed effects to infer to what extent these variables mediates the fitness premium in earnings. While the premium is unaffected when controlling for years of schooling it is lowered by half when controlling for occupation fixed effects (using 115 different occupational groups according to SSYK, the Standard for Swedish Occupational Classification, a three digit occupational classification code similar to the international classification, ISCO). Hence, more physically fit individuals are sorted into higher paying occupations. A related question is whether the fitness premium is the same along the earnings distribution.

Employing (conditional) quantile regressions including only age and physical fitness as regressors we find that the lowest decile depart somewhat in that the premium is found to be larger there (0.12), but is then quite similar to the mean (in Table 2) at the $25^{\text {th }}$, median, $75^{\text {th }}$ and $90^{\text {th }}$ percentile being $0.05,0.05,0.06$ and 0.08 respectively. Also, the result that non-cognitive skills mediates the fitness premium much more than cognitive skills hold for all these quantiles. These results are available upon request.
} 


\section{The field experiment}

\subsection{The experimental design}

The field experiment was conducted between March and November 2007. During this period all employment advertisements in selected occupations found on the webpage of the Swedish employment agency were collected. ${ }^{30}$ A clear majority of employers posting vacant jobs at this site want to have the job applications sent in by e-mail only. This facilitates our experimental design attaching information about sports skills to the job application since it can be done electronically. In total 8,500 applications were sent to 3,823 employers. ${ }^{31}$ Callbacks for interviews were received via telephone (voice mailbox) or e-mail. To minimize inconvenience to the employer invitations were promptly declined.

The applications had to be realistic while not referring to any real persons. Also, since the competition from other applicants was considerable the testers had to be representative of the average job applicant for that job. A number of real life (written) applications available on the webpage of the Swedish employment agency were used as templates and adjusted and calibrated for our purposes (see Appendix C for a template job application in the computer specialist occupation). Applicants also had varying amounts of work experience in the job applied for and had obtained their education in the same type of school, but at different locations. The application consisted of a quite general biography on the first page and a detailed $\mathrm{CV}$ of education and work experience on the second page. We proceed by explaining the design in more detail.

\section{Choice of occupations}

To make satisfactory progress in the collection of cases it was necessary that the demand for labor was relatively high in the chosen occupations. In addition, it was decided that the skill requirement and the degree of customer contact should vary across occupations.

\footnotetext{
${ }^{30}$ According to labor related laws all new vacancies should be reported to the Swedish employment agency. However, these laws are not enforced and all vacancies are therefore not reported. Still it is the one site where most vacant jobs are to be found.

${ }^{31}$ One, two and three job application(s), respectively, were sent to the same employer in 1,465, 39 and 2,319 instances.
} 
Hence, the selected occupations were both skilled and semi/unskilled and included a relatively high as well as a low contact with customers. In the end, the experiment was restricted to thirteen occupations. The selected occupations were computer professionals, construction work, business and shop sales assistants, accountants, nurses, restaurant workers (mostly waiters), vehicle drivers, machine operators, cleaning and three different types of teachers (match/science and language in upper level compulsory school and upper secondary school). Jobs were applied to all over Sweden, but most frequently in the two major cities of Sweden, Stockholm (59\%) and Gothenburg (24\%). For construction purposes, the applicants always signaled living in Stockholm or Gothenburg, see below for details.

\section{Variation of application information}

Typical corresponding testing (CT) studies vary only sex/ethnicity of the applicants by varying their names (see Rich and Riach, 2002). This study takes a more general approach by also varying other attributes. Hence, by this construction it is possible to measure the labor market return to different kinds of skills and attributes. However, the starting point is the same as for the standard CT, that is, to construct the desired general content of the resumes that should not vary. This is achieved at by using applications available on the webpage of the Swedish employment agency as templates, together with our experience from previous conducted field experiments, see Carlsson and Rooth (2007) and Rooth (2009). In footnote 8 we discussed this data having its origin in a large gender and ethnicity discrimination project. Hence, at this stage we also decided upon the names of the applicants, that is, having either a Swedish sounding male or female name or a Middle Eastern sounding name, varying over applications and being the same as in the previous experiments by Carlsson and Rooth (2007, 2008a, b).

After sketching the general frame of the applications we decided upon thirteen variables that could be important for the chance of being invited for interview. Formal education is varied such that the applicant can have either precisely the required education or to be overeducated. If the applicant is overeducated he/she is so in another field than the one searching for a job in. Having worked during summer holidays when in school takes a different value depending on whether this is the case or not. Also, the 
candidates could have spent a year during secondary school in a US high school, or not. Then two variables tell the personality of the candidate, that is, basically following the Big Five taxonomy using the categories extroversion and agreeableness, see Borghans et al. (2008).

In an ethnic discrimination context it is believed that the neighborhood in which the applicant lives in is important and therefore being included. This variable can take three values depending on the economic segregation in the area. Three additional variables relate to the applicant's unemployment experience. One variable indicates whether the applicant has been unemployed in-between different jobs, another whether the applicant was unemployed after finishing education or went directly to a first job, and finally, whether the applicant is unemployed or not at the moment, where the length of current unemployment spell varies between 3 and 9 months. In this context the number of previous employers is varied as well, being either 1 or 3 . These variables/attributes are at focus in other studies and therefore not commented upon further, but controlled for in the analysis. $^{32}$ One exception is job experience, which we include into the results section in order to relate the return to sports to. The above attributes make up a total of eleven different variables being manipulated in the job application. In Table A4 in the appendix the means of these variables, as well as their correlations are found, which reveals the randomness of the experimental design in that the correlations among variables is low. We now turn to the two prime attributes at focus in this study - the type of sport being engaged in and at what effort level. ${ }^{33}$

\footnotetext{
${ }^{32}$ Another variable that is of interest is of course the age of the applicant. It is however impossible to estimate an age effect by this construction because age is perfectly correlated with some of the other variables that we vary and given the values of these variables the age of the applicant is automatically given. For example, if the applicant turns nineteen when finishing secondary school in 2003 and then is unemployed for a year, finds a job and works for three years until "today" (summer 2007), the person must be 23 years old. In fact, all dates in an application, not only the age of the applicant, are automatically given and found by calculating backwards from the date when the resume was constructed, using time spent in employment, time spent in unemployment (before, after and in-between employment), time spent in university education and time spent abroad during secondary school.

${ }^{33}$ The reason for including information on leisure sports in the job application was to investigate whether adding such personal information would lessen the extent of ethnic/gender discrimination.
} 


\section{Signaling type of sports and on what effort level}

As mentioned in the introduction we expect being engaged in leisure sports as signaling (i) that good health improve productivity, (ii) having more social skills, and/or (iii) being more motivated/competitive. ${ }^{34}$ In order, at least loosely, to get an idea on if any of these explanations is plausible we have included different sports depending on to what extent we expect them to improve health through aerobic fitness, and to what extent they involve more or less social activities, that is, are performed by two people or more. As individual sports we choose to include tennis, golf, running/jogging and swimming and as team sports we included soccer and basketball. The individual sports of running/jogging and swimming are well known fitness sports, especially improving aerobic fitness and therefore being more related to a good health than the other included sports. Golf and tennis also improve aerobic fitness, but to a much lesser extent than running and swimming. On the other hand they require more social interactions. Especially golf has turned into one of the most popular sports in Sweden (and elsewhere). Soccer and basketball are in between as regards creating better health through aerobic fitness, but as team sports they probably incorporate more social interactions than the other included sports. Hence, if we find a variation in how different sports are valued by employers is this order coherent with a health or social interactions explanation?

Hence, the inclusion of these sports tells us whether there is a different labor market return to certain sports. But we also wanted to test whether there is a different labor market return to if the person previously in life was engaged in the sport on a (highly) competitive level, which is signaled in the text. This variation between competitive and recreational sports is expected to capture if recruiters value the motivation and/or competitiveness of job applicants. The sports were then also chosen if they were as likely to be engaged in on a competitive or a recreational level, and that both men and women are frequently engaged in them. Figure 2 gives the experimental design as regards the share of each sport and (previous) effort level. Sixty-two percent of the applications had a sport attached to it and of these about two thirds were individual sports and the other third

\footnotetext{
${ }^{34}$ However, alternative explanations do exist, for instance, that recruiters value persons engaged in certain sports higher since they themselves are engaged in them. Alternative explanations and extensions are discussed in the Conclusion.
} 
team sports. These specific sports are equally divided within these categories. Also, within each sport about half engage in it only for recreational purposes. Within the group not having sports in their application about half have the information "On evenings and weekends I enjoy my leisure time. Since we like to cook, and to have nice evenings at home, we often invite friends over for dinner" attached to it (the benchmark case in the regressions), while the other half signal being engaged in cultural activities.

The sports information was included as a separate section in the job application. For example, competitive soccer is signaled by the following sentences: "I spend quite a lot of time on physical activities when I don't work. Today I play in a lower soccer league than I used to, but it still involves training and matches several times a week". The recreational soccer player is instead signaled by: "Regarding my other interests I like to engage in recreational sport activities in order to stay in shape. For instance, during the summer season I play soccer in Korpen (a well known recreational sport league in Sweden)." The other sports are signaled in a similar way, see Appendix B.

\section{Construction of applications}

It was a demanding task to construct resumes with this great variation in attributes. First an application had to be divided into modules, in principle one module corresponding to each variable mentioned above. A module could look somewhat different depending on what variable it was linked to. Typically it could be a paragraph in the personal letter or a part of the $\mathrm{CV}$, or in some cases both. For example, the variable number of employers is first signaled by a paragraph in the letter telling the names of the employers and what tasks that where performed, and then also as an item in the CV stating the employer's names as well as the start and end dates for each employment.

Also, to utilize the number of advertised jobs to a maximum it was necessary to be able to send several applications to the same employer. To avoid suspiciousness the applications therefore had to be constructed in several versions with different typeface and layout. Three different versions with different looks depending on typeface and layout were allowed for. Hence, in addition to the thirteen randomly attached variables discussed above, the application version constitutes yet another variable, as does the order in which the applications are sent (if several are sent to the same employer), the city 
in which the applicant lives (Stockholm or Gothenburg) and the occupation the applicant applies for a job in.

The applicants always had postal addresses in Stockholm or Gothenburg for practical reasons. For example, it was only possible to have a limited number of telephone numbers with automatic answering machines for employers to call and therefore only a limited number of area codes as well. As stated previously, applications were not sent only to employers in these cities but to employers located everywhere in Sweden. When necessary a sentence was added to the application telling that the applicant was just about to move to the area where the employer was located. If the location of the employer was in Gothenburg then the applicant always lived in Gothenburg as well. If the location of the employer was somewhere else in Sweden, including Stockholm, then the applicant always lived in Stockholm.

The procedure of building a personal letter and a $\mathrm{CV}$ depending on randomized values of the variables had to be done in a very systematic way to avoid mistakes and to gain efficiency. Therefore a computer program was written in the programming language Visual Basic. The program was designed to do the following. The program started its execution by reading its input given by the research assistant. The inputs consisted of group belonging of the candidate (Swedish sounding male or female name or a Middle Eastern sounding name), the occupation to apply for job in, what layout to use on the application and in what city in Sweden the employer was located.

The second step was to randomly assign values to all variables that could vary. Depending on the values of the input the program randomly selected the corresponding modules and generated a complete application consisting of a personal letter on one page and a CV on another page. The program was extensively tested in order to verify that all modules fit together and that the result always was a realistic application.

Finally, the generated application was sent to the employer by email by the research assistant. In those cases where several applications were sent to the same employer the order of them was book kept (automatically by the computer program). That made it possible to control for sending order since it may influence the chance of being invited.

The e-mail addresses and the telephone numbers (including an automatic answering service) aiming for employers to make contact were registered at a large Internet provider 
and a phone company. From previous conducted field experiments we know that no (or very few) employers make contact through regular mail and therefore fictitious postal addresses are used in this study.

\subsection{Results for the field experiment}

In this section we analyze the effect of the manipulation of sports on the probability of being called for interview using probit regressions (reporting marginal effects from the dprobit command in Stata and clustering standard errors on the job level) where all models include the full set of randomly attached application attributes. ${ }^{35}$ The data for analysis include 5,657 and 2,843 male and female observations, respectively, found in Table 3.

\section{Sports skills and the probability to be invited for interview}

The analysis starts by regressing the callback dummy on the leisure sports indicator variable, work experience, cultural activity indicator, gender and ethnicity fixed effects as well as the full set of randomly attached worker attributes explained in Section 3.2 for the full sample of males and female job applicants. The first column and row of Table 3 (Model A) treats all sports as a single indicator variable and reveals that applications with sports attached to it have approximately a two percentage point higher probability of being called for interview compared to applications with no such information. This return is economically important and equivalent to the return to two years of additional work experience. In Model B the sports are divided into team and individual sports. While no statistically significant sports premium is found for team sports, the one for individual sports is. It amounts to being approximately equivalent to the return to two years of work experience, or raises the hiring probability for a job applicant by 2.3 percentage points. ${ }^{36}$

\footnotetext{
35 Since these attributes/variables were randomly attached to resumes we should not have to control for them. However, since the attributes are quite many and we in the empirical analysis sometimes use smaller samples we always include these controls. In almost all models being estimated the difference between including and not including them is negligible. The results in this section are also unaltered whether using the linear probability model or the margfx command in Stata.

${ }^{36}$ A test on if the estimates of individual and team sports are equal have a p-value of 0.4 .
} 
In Model $\mathrm{C}$ an indicator for each of the six sports are included into the regression with approximately 900 job applications being sent per sport. The sports having a statistically significant impact on the hiring probability are soccer and golf, with estimates of three and four percentage points, respectively. Also the estimates for jogging/running and tennis are large in magnitude, but estimated with a low precision. The result that not all sports are valued by employers, and especially golf being the sport valued the highest and swimming the lowest, indicate that the return to leisure sports does not have a health interpretation. On the other hand, that individual sports are more valued than team sports does not support the social network or skill interpretation.

Next, we test whether it makes a difference whether the leisure sport previously was engaged in on a (high) competitive level or not by testing this separately for team and individual sports, see model D. For this purpose we divide sports skills into four different categories, recreational team and individual sports and competitive team and individual sports. Hence, this comparison tells whether employers value sports for their recreational fitness effect only or if they value that being a sports participant signals being more motivated and more competitive. The estimate for competitive individual sports stands out as the one being both large in magnitude and being statistically significant. However, a test on if the two estimates of being engaged in the sport only on a recreational basis or previously at a more competitive level are equal, within team and individual sports, have a p-value of 0.9 and 0.3 , respectively. Hence, there is no evidence that recruiters value the competitive element in sports more than being engaged in it for only recreational purposes.

Last, we estimate the sports premium separately for job applications with a Swedish sounding male and female name and with a Middle Eastern sounding male name, with about 2,800 observations per group, see model E. While none of the estimates are statistically significant the ones for males are larger than the one for females. Before proceeding, we also state that there does not exist a return to being engaged in cultural activities in any of the models being estimated, while the return to work experience is about one percentage point per year worked.

Next we estimate the leisure sports premium within occupations, that is, estimating a model including occupation fixed effects (main effect) and then thirteen interactions for 
the sports indicator and occupation, see Table 4. A statistically significant sports premium is found in only two occupations, construction work and nursing. Also, these occupation specific sports premiums are very large in magnitude raising the probability of a callback for interview by seven and ten percentage points in nursing and construction work, respectively.

Given this result it is possible that the return to sports vary depending on how physically demanding a particular occupation is. We have implemented testing such a proposition in two directions. First, we have asked twenty-five employers and thirty-nine students to grade (important/not important) in which of the included occupations fitness is expected to be important for the productivity of workers. Almost everyone, both recruiters and students, responded that a good physical fitness is important for productivity in construction work, restaurant work, cleaning and nursing. Hence, these occupations are grouped into a category labeled physical occupations, while the rest of the occupations then constitute the category non-physical occupations, and then we estimate the sports premium separately within these two occupational categories, see Model B. Indeed, the sports premium is large in magnitude, about five percentage points, and statistically significant in occupations in which we would expect physical fitness to be important. Similarly, it is negligible in occupations not expected to be demanding a good physical fitness. Hence, contrary to the results for individual sports in Table 3 this result indicate that a good physical fitness might be an important characteristic of job applicants.

It can also be expected that high skilled jobs require less physically demanding job tasks. Hence, we have also divided the occupations according to the occupations skill level and constructed two aggregated occupational groupings of high and medium/low skilled occupations, see Model C. This information was taken from Statistic Sweden's occupational register (www.scb.se). We find no evidence of that the sports premium varies along skill requirement in the occupation. ${ }^{37}$

\footnotetext{
${ }^{37}$ It is possible that our other dimensions of sports, that is, team versus individual sports and competitive versus recreational level of sports, matters in jobs that require team work and a competitive personality, respectively. However, we do not know which jobs that require more team work or which jobs that are paid
} 
Given the variation in results depending on how occupations are grouped it seems relevant to re-estimate the models of Table 3 when grouping the data into physically demanding occupations and those which are not, see Table 5. Within the physical occupations category both applications signaling team and individual sports are found to have a large premium, being four and seven percentage points for individual and team sports, respectively (see Model A). ${ }^{38}$ When estimating the return to each sport separately we find the estimates to be large, above three percentage points, for all sports but swimming (Model B). Hence, these results are more indicate of a common sports premium possibly having a health-productivity explanation. Still, some sports are valued higher than others, but is only statistically significant for soccer, basketball and golf.

Again, we find no difference in the returns to sports depending on whether it signals having been active at a competitive level or only on a recreational level, see Model C. ${ }^{39}$ In this sub-sample the difference is even smaller than in Table 3, further reinforcing that motivation/competitiveness is not valued by employers in relation to sports. ${ }^{40}$ Finally, we do not find a single estimate to be statistically significant within the non-physical occupations category. However, the returns to soccer, golf and tennis are above two percentage points.

Dividing the data down further to smaller sub-groups results in that sometimes the estimates become too large to be reliable/sensible. Hence, the analysis that follows must be read with these concerns in mind. First, we estimate separate sports premiums by gender and ethnicity, and then merge the two samples of males into one data set, see Table 6. The results for Model A states that individual sports seem to have a larger return than team sports for native males, while the opposite holds for native females. For ethnic minority males we do not find a difference in the premium for team and individual sports.

by piece rates. At the end of this section, however, we test whether being engaged in competitive sports matters for sales people, that is, within sales occupations.

${ }^{38}$ The difference in estimates is not statistically significant.

${ }^{39}$ The differences in estimates are not statistically significant, with a p-value of above 0.9 in both instances.

40 An alternative interpretation is that our signal of being competitive is not observed by employers. However, when asking colleagues at work if the texts on recreational and competitive sports signal just that, their answers clearly indicate that in the affirmative. 
Since none of the estimates is statistically significant it is however questionable to view these results as a gender difference.

There is also a difference by gender and ethnicity in which sports that are valued the most. The highest premiums are for native men found for golf and tennis, for native women for golf and soccer, and for ethnic minority males for soccer and jogging. However, only the premium to golf and tennis for native males are statistically significant. Also the return to work experience varies somewhat across the three groups and is the highest for native women, followed by ethnic minority males, and then native men, with a statistically insignificant return to work experience. While the return to cultural activities is large for native men, it is statistically insignificant for all three groups.

Since women stand out as being differently valued compared to men on sports, and the two males groups being valued similarly, we finally group the two male samples into one and estimate the same models as above. The return to individual sports is statistically significant and amounts to three percentage points, while the return to team sports is basically zero. In this data we also find that soccer, jogging/running, golf and tennis to have a similar return of around three percentage points, while the return to basketball and swimming is negligible.

So far the return to previously having been engaged in a sport on a competitive level has been found to be no different than the return to sports on a recreational level. However, being competitive might be especially important in sales occupations, that is, in business and shop sales. Grouping these two occupations and estimating Model D of Table 3 we find that having been engaged in sports on a competitive level is always valued higher than being engaged in it only on a recreational level, but this difference is not statistically significant in this specification either.

\section{Conclusion}

In this study we set out to investigate whether physical fitness, measured by the persons oxygen uptake, or participating in leisure sports have a positive impact on labor market outcomes, that is, earnings and callbacks for a job interview. First, employing a data set on physical fitness measured at age 18 when enlisting and adult earnings and using no 
other controls in the regression equation other than physical fitness and age, we find that a one standard deviation in physical fitness is associated with an earnings premium of around seven percent. Netting out unobservable family variables affecting this association by using a sibling fixed effects model the premium is reduced to four percent. It could be noted that the fitness premium then closely corresponds to the return to one additional year of schooling, which is around five percent in Sweden (using the data explored in this study). ${ }^{41}$ Second, employing data that was collected within a field experiment on ethnic and gender discrimination this is the first study to analyze the return to leisure sports in the regular labor market using fictitious job applications. In this hiring experiment we find that job applications signaling being engaged in a leisure sport have a two percentage point higher probability to receive a callback for interview, which is equivalent to the return to 1.5 additional years of work experience.

Hence, these results indicate that the public interest in having a good health, and the possible productivity enhancing effect from it, is mirrored in the employers evaluations of worker health/fitness. However, more in depth analyses render such a conclusion to be premature. The results using register information on adult earnings and physical fitness point in the direction that sports and non-cognitive skills are much related and explains about two thirds of the sports-earnings association. Also the field experiment gives similar second stage results in that some sports, that is, soccer, tennis and golf, are valued higher than the more fitness related sports of running/jogging and swimming. What characterizes the former sports is that they are foremost popular social sports.

However, dividing the data into jobs that are physically demanding and those that are not we find more or less all sports to be valued by employers again supporting a healthproductivity explanation. Finally, we find a gender difference in that males are valued on if being engaged in leisure sports, while females are not.

Even if this field experimental data is unique it is not perfect and could be improved in several directions. First, the result that golf and soccer are valued the most by

\footnotetext{
${ }^{41}$ This is much lower than the ten percent return to education in the US, which is explained by the institutional setting in Sweden, with the existence of "solidarity" wages and a rather narrow wage distribution. In Sweden, the $90^{\text {th }}$ percentile earns approximately twice as much as the $10^{\text {th }}$ percentile, whereas in the US they earn five times as much.
} 
employers raises the question to what extent these results are driven by specific, for us unknown, recruiter characteristics rather by a value attached to the sport itself? In this respect the present study could probably be improved considerably if more information would be known about the recruiter. It would be interesting to analyze whether the gender of the recruiter affect the variation in the sports premium by men and women - is it male recruiters who find sporting women no different than no-sporting ditos? In addition, it would be equally interesting to know what sports the recruiters favor of their own. If their evaluation is mirroring their own interests they might be sorting applicants similarity to their own life style, rather than on a sport signaling some positive personal attribute. For instance, if many recruiters themselves play golf they might be favoring another golfer and attach positive values to such life styles.

To conclude, even though this study improves the knowledge on what employers value when hiring, some questions arise as to what we have found. Most surprising (to us) is the fact that we do not find that all employers, irrespective of sector, value a healthy life style, given all the positive values being associated with such personality in everyday life. If so, recruiters would value job applicants engaged in running, jogging and swimming more, but they don't. Also, it is somewhat surprising that the sports premium is not related to being more competitive. Overall, the small association of a positive health profile with labor market outcomes is in accordance with previous results in the health literature (Currie and Mandrian, 1999). 


\section{References}

Averett, S. and Korenman, S. (1996) “The Economic Reality of the Beauty Myth", Journal of Human Resources, 31(2):304-30.

Barron, J., B. T. Ewing, and G. R. Waddell (2000) "The Effects of High School Athletic Participation on Education and Labor Market Outcomes", The Review of Economics and Statistics, 82:409-421.

Behrman, Jere R., and Mark R. Rosenzweig (2001) “The Returns to Increasing Body Weight”, University of Pennsylvania WP 01-052. Philadelphia.

Bertrand, M. and Mullainathan, S. (2004) "Are Emily and Greg More Employable than Lakisha and Jamal? A Field Experiment on Labor Discrimination", American Economic Review, 991-1014.

Blanden, J., Gregg, P., and Macmillan, L. (2007) "Accounting for Intergenerational Income Persistence: Non-Cognitive Skills, Ability and Education", The Economic Journal, 117 (March), C43-C60.

Borghans, L., Duckworth, A., Heckman J., and ter Weel B. (2008) "The Economics and Psychology of Personality Traits", Journal of Human Resources, 43(4): 972-1059.

Bowles, S., Gintis, H. and M. Osborne (2001) "The Determinats of Earnings: A Behavioral Approach", Journal of Economic Literature, 39(4): 137-1177.

Card, D. (1999) "The Return to Education", in Ashenfelter O, Card D (eds) Handbook of Labor Economics, pp. 1801-1863. Elsevier. Amsterdam.

Carlsson, M. and Rooth, D. (2007) "Evidence of Ethnic Discrimination in the Swedish Labor Market Using Experimental Data", Labour Economics, vol 14(4), pp. 716-729.

Carlsson, M. and Rooth, D. (2007) "Evidence of Ethnic Discrimination in the Swedish Labor Market Using Experimental Data”, Labour Economics, vol 14(4), pp. 716-729.

Carlsson, M. and Rooth, D. (2008a) "Is It Your Foreign Name or Foreign Qualifications? An Experimental Study of Ethnic Discrimination in Hiring", IZA Discussion Paper \#3810.

Carlsson, M. and Rooth, D. (2008b) "An Experimental Study of Sex Segregation in the Swedish Labour Market: Is Discrimination the Explanation?", IZA Discussion Paper \#3811.

Carroll, J. (1993) Human cognitive abilities. A survey of factor-analytic studies, Cambridge: University Press. 
Case, A. and Paxson, C. (2008) "Stature and status: Height, ability, and labor market outcomes", Journal of Political Economy, 116(3):499-532.

Cawley, John. (2004) “The Impact of Obesity on Wages”, Journal of Human Resources 39(2):451-74.

Currie, J and Mandrian (1999) "Health, Health Insurance and the Labor Market", in Ashenfelter O, Card D (eds) Handbook of Labor Economics, pp. 3309-3416. Elsevier. Amsterdam.

Duckworth, AL., and Seligman, MEP. (2005) "Self-Discipline Outdoes IQ in Predicting Academic Performance of Adolescents", Psychological Science 16(12): p 939-944.

Ewing, B. T. (1998) “Athletes and Work”, Economics Letters, 59: 113-117.

Ewing, B. T. (2007) "The Labor Market Effects of High School Athletic Participation: Evidence From Wage and Fringe Benefit Differentials", Journal of Sports Economics, 8, 255-265.

Farrell, L., and M. A. Shields (2002) "Investigating the economic and demographic determinants of sporting participation in England", Journal of the Royal Statistical Society A, 165, 335-348.

Fenstein (2000) "The Relative Economic Importance of Academic, Psychological, and Behavioural Attributes Developed in Childhood". CEP Discussion Paper.

Fink, B., Neave, N. and Seydel, H. (2007) "Male facial appearance signals physical strenght to women", American Journal of Human Biology, 19:82-87.

Gale, C, M. Cooper, and Sayer, A.A. (2007). Grip strength, body

composition, and mortality. Int J Epidemiol, 36:228-35.

Gale, C., Martyn, C., Cooper, C., and Sayer, A. (2007) "Grip strength, body composition, and mortality", International Journal of Epidemiology, 36:228-35.

Gratton, C., and P. Taylor (2000) The Economics of Sport and Recreation, London: Taylor and Francis.

Hamermesh, D., and J. Biddle (1994) "Beauty and the Labor Market", American Economic Review, 84(5):1174-94.

Harper, B. (2000) "Beauty, Stature, and the Labour Market: A British Cohort Study", Oxford Bulletin of Economics and Statistics, 62(1):771-800.

Heckman, J. and Rubinstein (2001) "Importance of Noncognitive Skills: Lessons from the GED Testing Program”, American Economic Review, 91 (2), 145-149. 
Heckman, J.J., Stixrud, J, and Urzua, S. (2006) "The Effects of Cognitive and Noncognitive Abilities on Labor Market Outcomes and Social Behavior", Journal of Labor Economics, 24(3), 411-482.

Hyde, T. and M. Gegenbach (2007) Conservative Management of Sports Injuries. 2nd ed; Sudbury, Mass. Jones \& Bartlett.

Kahn, L. (2000) "The Sports Business as a Labor Market Laboratory", Journal of Economic Perspectives 14:3, 75-94.

Lechner, M. (2009) "Long-run labour market and health effects of individual sports activities", Journal of Health Economics. 28(4): 839-854.

Lindqvist, E, and R. Vestman (2009) "The Labor Market Returns to Cognitive and Noncognitive Ability: Evidence from the Swedish Enlistment", IFN (Research Institute of Industrial Economics) Working Paper No. 794.

Long, J. E., and S. B. Caudill (2001) "The Impact of Participation in Intercollegiate Athletics on Income and Graduation", The Review of Economics and Statistics, 73, 525531.

Lundborg, P, Nystedt, P and Rooth D (2009a) "BMI and Earnings: The role of aerobic fitness and cognitive and non-cognitive skills", manuscript. Lund University.

Lundborg, P, Nystedt, P and Rooth D (2009b) "The Height Premium in Earnings: The Role of Physical Capacity and Cognitive and Non-Cognitive Skills", IZA Discussion Paper \#4266. IZA, Bonn.

Mobius, M., and T. Rosenblat (2006) "Why Beauty Matters", American Economic Review, 96(1):222-35.

Neal, D. and Johnson, W. (1996) "The Role of Premarket Factors in Black-White Wage Differences”, Journal of Political Economy, 104 (4): 869-895.

Pagan, J., and A. Davlia (1997) "Obesity, Occupational Attainment and Earnings", Social Science Quarterly 8(3):756-770.

Persico, N., A. Postlewaite, and D. Silverman (2004) "The Effect of Adolescent Experience on Labor Market Outcomes: The Case of Height", Journal of Political Economy, 112, 1019-1053.

Rashad, I. (2007) "Cycling: An Increasingly Untouched Source of Physical and Mental Health”, NBER Working Paper 12929. 
Register, C., and D. Williams (1990) "Wage Effects of Obesity Among Young Workers" Social Science Quarterly, 71(1):130-41.

Riach, P. A. and Rich, J. (2002) "Field experiments of discrimination in the market place", The Economic Journal, 112:F480-F518.

Rooth, D. (2009) "Obesity, attractiveness and differential treatment in hiring - a field experiment", Journal of Human Resources.

Rottenberg S. (1956) "The Baseball Player's Labor Market", Journal of Political Economy, Vol. 64 (3):242-258.

Ruhm, C. J. (2007) "Current and Future Prelevence of Obesity and Severe Obesity in the United States", Forum for Health Economics \& Policy, 10 (2), Article 6, 1-26.

Sloane, P. (2006) "Rottenberg and the Economics of Sport after 50 Years: An Evaluation", IZA DP\#2175. Iza, Bonn. 


\section{Figures:}

Figure 1. (Log) Earnings and physical fitness. Total population.

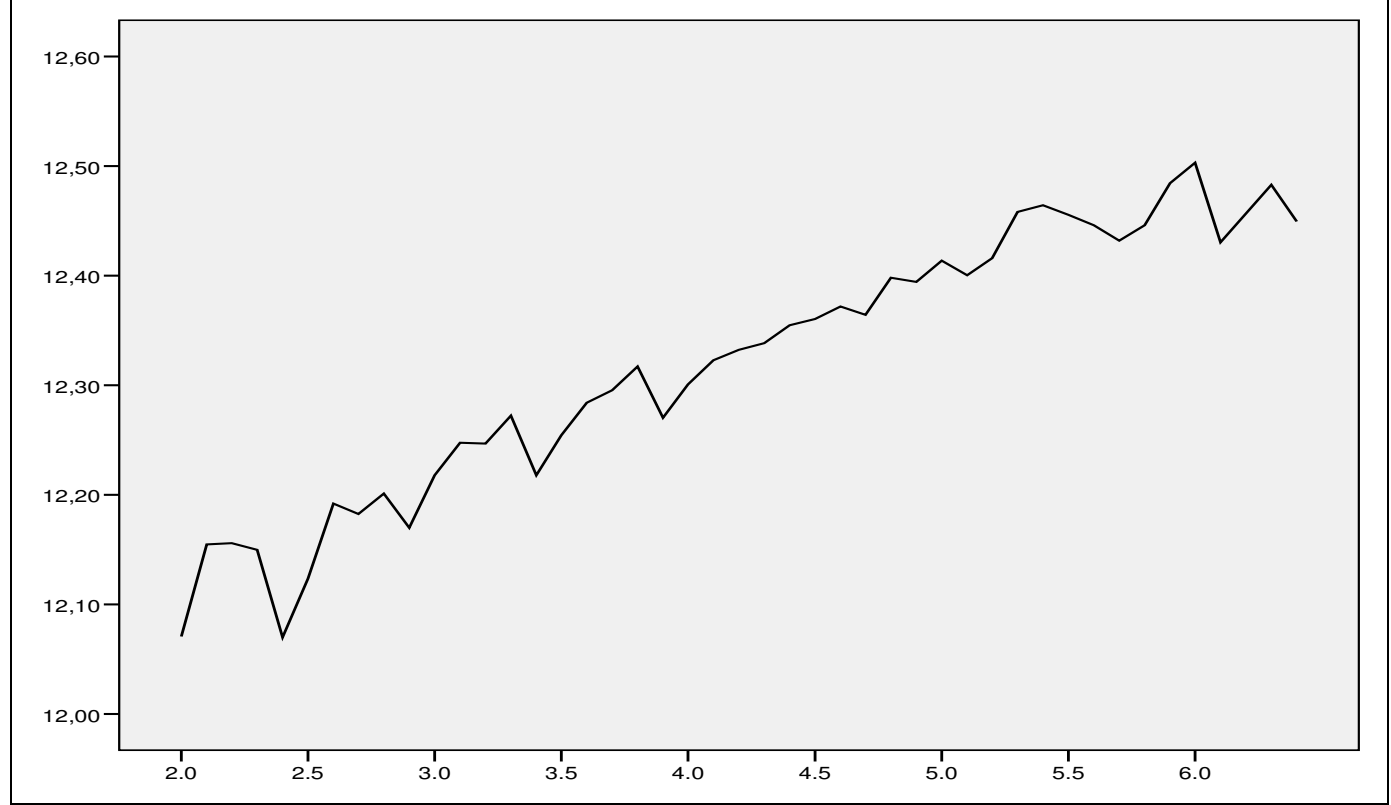

Note: The dependent variable is the mean for everyone with the integer value of the independent variable, being truncated at 2.0 and 6.4, having a mean of 4.3 and a standard deviation of 0.7 . 
Figure 2. Experimental design, $\mathrm{n}=8,500$ job applications

\begin{tabular}{|l|l|}
\hline \multicolumn{1}{|c|}{$\begin{array}{l}\text { Sports }(62 \%) \\
\mathrm{n}=5,300\end{array}$} \\
\hline \begin{tabular}{|l|l|} 
Team sports \\
$\mathrm{n}=1,789$
\end{tabular} \\
\hline $\begin{array}{l}\text { Recreational or competitive level } \\
\text { Soccer }\end{array}$ \\
\hline Basketball & $\begin{array}{l}\text { Jogging/running } \\
\text { Swimming } \\
\text { Golf } \\
\text { Tennis }\end{array}$ \\
\hline
\end{tabular}

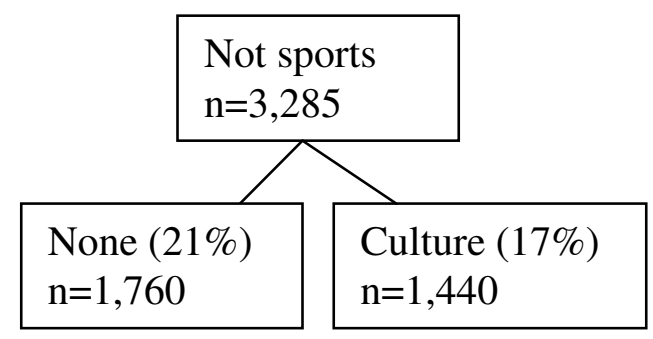




\section{Tables:}

Table 1. Descriptives of the population divided at physical fitness below and above the mean (4.31). Men 28-38 years old, 2003. Siblings (brothers).

\begin{tabular}{lrrrr}
\hline Variables & $<4.31$ & & & $>4.31$ \\
\hline Physical fitness & 3.73 & $(0.45)$ & 4.87 & $(0.41)$ \\
Logarithm annual earnings & 12.28 & $(0.78)$ & 12.40 & $(0.75)$ \\
& & & & \\
Age & 33.3 & $(3.2)$ & 32.9 & $(2.8)$ \\
Parental characteristics: & & & & \\
Fathers' (log) earnings & 11.02 & $(0.50)$ & 11.11 & $(0.50)$ \\
Mothers' (log) earnings & 9.63 & $(1.35)$ & 9.68 & $(1.35)$ \\
Fathers years of schooling & 11.0 & $(2.1)$ & 11.6 & $(2.4)$ \\
Mothers years of schooling & 11.1 & $(2.1)$ & 11.6 & $(2.3)$ \\
Cognitive skill: & 4.8 & $(1.9)$ & 5.4 & $(1.8)$ \\
Non-cognitive skill: & 4.5 & $(1.8)$ & 5.6 & $(1.7)$ \\
Handgrip strength, & 621 & $(100)$ & 613 & $(93)$ \\
Height & 180.0 & $(6.5)$ & 178.9 & $(6.3)$ \\
BMl & 22.6 & $(3.4)$ & 21.1 & $(1.9)$ \\
No of observations & & & & 74,264 \\
\hline
\end{tabular}

Notes: Standard deviations in parentheses. The variables on cognitive skill, non-cognitive skill and

physical capacity are standardized when used in the empirical analysis. See also Table A1 in the appendix for descriptives of the total population of men. 
Table 2. The physical fitness premium. Men 28-38 years old, 2003. Logarithm of annual earnings. Siblings data.

\begin{tabular}{|c|c|c|c|c|c|c|c|c|}
\hline Outcome and controls & $A$ & $\mathrm{~B}$ & $\mathrm{C}$ & $\mathrm{D}$ & $E$ & $\mathrm{~F}$ & $\mathrm{G}$ & $\mathrm{H}$ \\
\hline \multicolumn{9}{|l|}{ Log Earnings: } \\
\hline Physical fitness ( $\left.W_{\max } / \mathrm{kg}\right)$ : & $\begin{array}{c}0.074^{* * *} \\
(0.001) \\
0.02\end{array}$ & $\begin{array}{c}0.073^{* * *} \\
(0.002) \\
0.02\end{array}$ & $\begin{array}{c}0.061^{* * *} \\
(0.002) \\
0.03\end{array}$ & $\begin{array}{c}0.041^{* * *} \\
(0.003) \\
0.02\end{array}$ & $\begin{array}{c}0.046^{\star \star *} \\
(0.003) \\
0.03\end{array}$ & $\begin{array}{c}0.032^{* * *} \\
(0.003) \\
0.04\end{array}$ & $\begin{array}{c}0.017^{* * *} \\
(0.003) \\
0.05\end{array}$ & $\begin{array}{c}0.017^{\star \star \star} \\
(0.004) \\
0.06\end{array}$ \\
\hline \multicolumn{9}{|l|}{ Years of schooling: } \\
\hline Physical fitness $\left(W_{\max } / \mathrm{kg}\right)$ : & $\begin{array}{c}0.507^{\star \star *} \\
(0.003)\end{array}$ & $\begin{array}{c}0.530^{* * *} \\
(0.005)\end{array}$ & $\begin{array}{c}0.364^{* * *} \\
(0.005)\end{array}$ & $\begin{array}{c}0.218^{* * *} \\
(0.007)\end{array}$ & $\begin{array}{c}0.238^{* * *} \\
(0.007)\end{array}$ & $\begin{array}{c}0.148^{* * *} \\
(.006)\end{array}$ & $\begin{array}{c}0.132^{\star * *} \\
(.007)\end{array}$ & $\begin{array}{c}0.117^{\star * *} \\
(0.007)\end{array}$ \\
\hline R2 & 0.07 & 0.07 & 0.25 & 0.07 & 0.09 & 0.35 & 0.14 & 0.36 \\
\hline \multicolumn{9}{|l|}{ Controls for: } \\
\hline Parental income and schooling & - & - & yes & - & & & & \\
\hline BMI and height: & - & - & - & - & yes & - & - & yes \\
\hline Cognitive skill: & - & - & - & - & - & yes & - & yes \\
\hline Non-cognitive skill: & - & - & - & - & - & - & yes & yes \\
\hline Sibling fixed effect & no & no & no & yes & yes & yes & yes & yes \\
\hline No of cases & 446,930 & 144,671 & 144,671 & 144,671 & 144,671 & 144,671 & 144,671 & 144,671 \\
\hline
\end{tabular}

Notes: This table reports estimates from the (1) regression model: Log Earnings $=\mathrm{a}+\mathrm{b} *$ Physical fitness $+\mathrm{c} * \mathrm{X}+\mathrm{f}+\mathrm{e}$. Model A only includes physical fitness and age fixed effects and is estimated using OLS for the total data. Model B restricts the data to siblings estimating the same model as in Model A, while mode $\mathrm{C}$ also adds parental characteristics. Model D include only sibling fixed effects. Model E adds height and BMI to Model D, while Model F adds cognitive skill, Model $\mathrm{G}$ adds non-cognitive skill, and Model $\mathrm{H}$ includes all variables. 
Table 3. The return to leisure sports for different subgroups in the field experiment. Marginal effects (percentage points). Men and women.

\begin{tabular}{|c|c|c|c|c|c|}
\hline & $\mathrm{A}$ & $\mathrm{B}$ & C & $\mathrm{D}$ & $E$ \\
\hline Sports for total data $(n=8,500)$ & $\begin{array}{c}0.020^{*} \\
{[0.012]}\end{array}$ & - & - & - & - \\
\hline \multicolumn{6}{|l|}{ By team and individual sports: } \\
\hline Team sports $(n=1,789)$ & - & $\begin{array}{c}0.014 \\
{[0.015]}\end{array}$ & - & - & - \\
\hline Individual sports $(n=3,511)$ & - & $\begin{array}{c}0.023^{*} \\
{[0.012]}\end{array}$ & - & - & - \\
\hline \multicolumn{6}{|l|}{ By sports: } \\
\hline Soccer $(n=906)$ & - & - & $\begin{array}{c}0.032^{*} \\
{[0.018]}\end{array}$ & - & - \\
\hline Basketball $(n=883)$ & - & - & $\begin{array}{l}-0.005 \\
{[0.018]}\end{array}$ & - & - \\
\hline Jogging/running (n=904) & - & - & $\begin{array}{c}0.025 \\
{[0.018]}\end{array}$ & - & - \\
\hline Swimming $(n=889)$ & - & - & $\begin{array}{c}-0.004 \\
{[0.017]}\end{array}$ & - & - \\
\hline Golf ( $n=902)$ & - & - & $\begin{array}{l}0.043^{* *} \\
{[0.018]}\end{array}$ & - & - \\
\hline Tennis ( $n=816)$ & - & - & $\begin{array}{c}0.028 \\
{[0.019]}\end{array}$ & - & - \\
\hline \multicolumn{6}{|l|}{ By competitive/recreational level: } \\
\hline Recreational team sports ( $n=924)$ & - & - & - & $\begin{array}{c}0.015 \\
{[0.018]}\end{array}$ & - \\
\hline Competitive team sports $(n=865)$ & - & - & - & $\begin{array}{c}0.013 \\
{[0.018]}\end{array}$ & - \\
\hline Recreational individual sports $(n=1,866)$ & - & - & - & $\begin{array}{c}0.019 \\
{[0.014]}\end{array}$ & - \\
\hline Competitive individual sports $(n=1,645)$ & - & - & - & $\begin{array}{c}0.028^{*} \\
{[0.015]}\end{array}$ & - \\
\hline \multicolumn{6}{|l|}{ By gender and ethnicity: } \\
\hline Native males $(n=2,837)$ & - & - & - & - & $\begin{array}{c}0.018 \\
{[0.022]}\end{array}$ \\
\hline Native females $(n=2,843)$ & - & - & - & - & $\begin{array}{c}0.010 \\
{[0.021]}\end{array}$ \\
\hline Ethnic minority males $(n=2,820)$ & - & - & - & - & $\begin{array}{c}0.029 \\
{[0.018]}\end{array}$ \\
\hline \multicolumn{6}{|l|}{ Other returns: } \\
\hline Work experience (1-5 years) & $\begin{array}{l}0.010^{* *} \\
{[0.004]}\end{array}$ & $\begin{array}{l}0.010^{* *} \\
{[0.004]}\end{array}$ & $\begin{array}{l}0.010^{* *} \\
{[0.004]}\end{array}$ & $\begin{array}{l}0.010^{\star *} \\
{[0.004]}\end{array}$ & - \\
\hline Cultural activities $(n=1,486)$ & $\begin{array}{c}0.005 \\
{[0.015]}\end{array}$ & $\begin{array}{c}0.005 \\
{[0.015]}\end{array}$ & $\begin{array}{c}0.005 \\
{[0.015]}\end{array}$ & $\begin{array}{c}0.002 \\
{[0.014]}\end{array}$ & - \\
\hline
\end{tabular}

Notes: This table reports marginal effects for the probability of being invited for an interview based on probit regressions. Model A reports the marginal effect of having sports in the job application, as opposed to not having it, and in addition controls for cultural activities, work experience, gender, ethnicity, and the full vector $X$ including all attributes discussed in Section 3.2 using the model Prob (Callback=1) $=a+b^{*}$ Sports + $\mathrm{c}^{*}$ Exp $+\mathrm{d}^{*}$ Culture $+\mathrm{e}^{*}$ Female $+\mathrm{f}^{*}$ Ethnic $+\mathrm{g} * \mathrm{X}$. Model B divides sports into team and individual sports, while Model $\mathrm{C}$ includes an indicator variable for each sport. Model D then distinguishes between presenting the team and individual sports as on a recreational or competitive level. Finally, Model E presents estimates for sports by gender and ethnicity by estimating separate regressions by gender and ethnicity using the model Prob $($ Callback $=1)=a+b *$ Sports $+c * E x p+d *$ Culture $+e^{*} X$. Since each regression then has its own returns to experience and cultural activities these are not shown. *,**, and *** denote the 10, 5 and 1 percent significance level, respectively. Reported standard errors (in brackets) are adjusted for clustering on the job. 
Table 4. The return to sports for different subgroups. Marginal effects (percentage points).

\begin{tabular}{|c|c|c|c|}
\hline Variable & $A$ & $\mathrm{~B}$ & $\mathrm{C}$ \\
\hline \multicolumn{4}{|l|}{ By occupation: } \\
\hline Shop sales $(n=1,135)$ & $\begin{array}{l}-0.008 \\
{[0.032]}\end{array}$ & - & - \\
\hline Construction work ( $n=473$ ) & $\begin{array}{l}0.097^{* *} \\
{[0.049]}\end{array}$ & - & - \\
\hline Computer specialists $(n=990)$ & $\begin{array}{c}0.005 \\
{[0.026]}\end{array}$ & - & - \\
\hline Vehicle drivers $(n=703)$ & $\begin{array}{c}0.038 \\
{[0.035]}\end{array}$ & - & - \\
\hline Business sales $(n=1,513)$ & $\begin{array}{c}0.035 \\
{[0.024]}\end{array}$ & - & - \\
\hline Teachers (math, $n=348$ ) & $\begin{array}{c}0.028 \\
{[0.047]}\end{array}$ & - & - \\
\hline Teachers (secondary school, $n=447$ ) & $\begin{array}{c}0.025 \\
{[0.039]}\end{array}$ & - & - \\
\hline Accountants $(n=627)$ & $\begin{array}{l}-0.034 \\
{[0.032]}\end{array}$ & - & - \\
\hline Restaurant work $(n=580)$ & $\begin{array}{l}-0.025 \\
{[0.032]}\end{array}$ & - & - \\
\hline Nurses $(n=445)$ & $\begin{array}{l}0.072^{*} \\
{[0.041]}\end{array}$ & - & - \\
\hline Teachers (languages, n=316) & $\begin{array}{c}0.008 \\
{[0.056]}\end{array}$ & - & - \\
\hline Cleaning $(n=555)$ & $\begin{array}{c}0.065 \\
{[0.055]}\end{array}$ & - & - \\
\hline Machine operators $(n=368)$ & $\begin{array}{l}-0.057 \\
{[0.034]}\end{array}$ & - & - \\
\hline \multicolumn{4}{|l|}{ Physical occupations: } \\
\hline Physical $(n=2,053)$ & - & $\begin{array}{l}0.049 * * \\
{[0.023]}\end{array}$ & - \\
\hline Non-physical $(n=6,447)$ & - & $\begin{array}{c}0.010 \\
{[0.013]}\end{array}$ & - \\
\hline \multicolumn{4}{|l|}{ By skills: } \\
\hline Highly skilled $(n=3,173)$ & - & - & $\begin{array}{c}0.014 \\
{[0.021]}\end{array}$ \\
\hline Medium/low skilled ( $n=5,327)$ & - & - & $\begin{array}{c}0.021 \\
{[0.014]}\end{array}$ \\
\hline \multicolumn{4}{|l|}{ Other returns: } \\
\hline Work experience & $\begin{array}{c}0.012^{* * *} \\
{[0.004]}\end{array}$ & - & - \\
\hline Cultural activities & $\begin{array}{c}0.003 \\
{[0.014]}\end{array}$ & - & - \\
\hline
\end{tabular}

Notes: This table reports marginal effects for the probability of being invited for an interview based on probit regressions. Model A reports the marginal effect of having sports in the job application for each occupation using the model Prob $($ Callback $=1)=a+b *[$ Sports*Occ $]+c^{*}$ Exp $+d^{*}$ Culture $+e^{*}$ Female $+f^{*}$ Ethnic + $\mathrm{g} *$ Occ. Model B and C use the same model as in Table 3, but aggregates the separate occupations to those that require a physical profile or high skills, respectively. Physical occupations include construction work, restaurant work, nurses, and cleaning, while Non-physical include all other occupations. Highly skilled occupations include computer specialists, all categories of teachers, accountants, and nurses, while Low skilled include all other occupations. *, **, and *** denote the 10, 5 and 1 percent significance level, respectively. Reported standard errors (in brackets) are adjusted for clustering on the job. 
Table 5. The return to sports for different subgroups. Marginal effects (percentage points).

\begin{tabular}{|c|c|c|c|c|c|c|}
\hline \multirow[b]{2}{*}{ Variable } & \multicolumn{3}{|c|}{ Physical occupations ( $n=2,053)$} & \multicolumn{3}{|c|}{ None-physical occupations ( $n=6,447)$} \\
\hline & A & $\mathrm{B}$ & $\mathrm{C}$ & $A$ & B & $\mathrm{C}$ \\
\hline \multicolumn{7}{|l|}{ By team and individual sports: } \\
\hline Team sports & $\begin{array}{l}0.067^{* *} \\
{[0.031]}\end{array}$ & - & - & $\begin{array}{c}-0.002 \\
{[0.017]}\end{array}$ & - & - \\
\hline Individual sports & $\begin{array}{c}0.043^{*} \\
{[0.026]}\end{array}$ & - & - & $\begin{array}{c}0.017 \\
{[0.014]}\end{array}$ & - & - \\
\hline \multicolumn{7}{|l|}{ By sports: } \\
\hline Soccer & - & $\begin{array}{l}0.072^{* *} \\
{[0.039]}\end{array}$ & - & - & $\begin{array}{c}0.021 \\
{[0.021]}\end{array}$ & - \\
\hline Basketball & - & $\begin{array}{c}0.064^{*} \\
{[0.039]}\end{array}$ & - & - & $\begin{array}{c}-0.024 \\
{[0.020]}\end{array}$ & - \\
\hline Jogging/running & - & $\begin{array}{c}0.057 \\
{[0.038]}\end{array}$ & - & - & $\begin{array}{c}0.015 \\
{[0.020]}\end{array}$ & - \\
\hline Swimming & - & $\begin{array}{c}-0.007 \\
{[0.037]}\end{array}$ & - & - & $\begin{array}{c}-0.002 \\
{[0.020]}\end{array}$ & - \\
\hline Golf & - & $\begin{array}{c}0.088^{\star * *} \\
{[0.038]}\end{array}$ & - & - & $\begin{array}{c}0.026 \\
{[0.020]}\end{array}$ & - \\
\hline Tennis & - & $\begin{array}{c}0.032 \\
{[0.038]}\end{array}$ & - & - & $\begin{array}{c}0.029 \\
{[0.022]}\end{array}$ & - \\
\hline \multicolumn{7}{|l|}{ By competitive/recreational: } \\
\hline Recreational team sports & - & - & $\begin{array}{l}0.068^{*} \\
{[0.039]}\end{array}$ & - & - & $\begin{array}{c}-0.001 \\
{[0.020]}\end{array}$ \\
\hline Competitive team sports & - & - & $\begin{array}{l}0.067^{*} \\
{[0.040]}\end{array}$ & - & - & $\begin{array}{c}-0.002 \\
{[0.020]}\end{array}$ \\
\hline Recreational individual sports & - & - & $\begin{array}{c}0.047 \\
{[0.030]}\end{array}$ & - & - & $\begin{array}{c}0.011 \\
{[0.016]}\end{array}$ \\
\hline Competitive individual sports & - & - & $\begin{array}{c}0.041 \\
{[0.032]}\end{array}$ & - & - & $\begin{array}{c}0.024 \\
{[0.017]}\end{array}$ \\
\hline \multicolumn{7}{|l|}{ Other returns: } \\
\hline Work experience & $\begin{array}{c}0.007 \\
{[0.009]}\end{array}$ & $\begin{array}{c}0.007 \\
{[0.009]}\end{array}$ & $\begin{array}{c}0.007 \\
{[0.009]}\end{array}$ & $\begin{array}{l}0.011^{\text {* }} \\
{[0.005]}\end{array}$ & $\begin{array}{l}0.011^{* *} \\
{[0.005]}\end{array}$ & $\begin{array}{l}0.011^{\text {** }} \\
{[0.005]}\end{array}$ \\
\hline Cultural activities & $\begin{array}{c}0.009 \\
{[0.032]}\end{array}$ & $\begin{array}{c}0.009 \\
{[0.032]}\end{array}$ & $\begin{array}{c}0.009 \\
{[0.032]}\end{array}$ & $\begin{array}{c}0.002 \\
{[0.016]}\end{array}$ & $\begin{array}{c}0.002 \\
{[0.016]}\end{array}$ & $\begin{array}{c}0.002 \\
{[0.016]}\end{array}$ \\
\hline
\end{tabular}

Notes: This table reports marginal effects for the probability of being invited for an interview based on probit regressions for physical and non-physical occupations separately. Model A divides sports into team and individual sports, while Model B includes an indicator variable for each sport, and in addition controls for cultural activities, work experience, gender, ethnicity, and the full vector $\mathrm{X}$ including all attributes discussed in Section 3.2 using the model Prob (Callback=1) $=\mathrm{a}+\mathrm{b} *$ Sports $+\mathrm{c}^{*} \operatorname{Exp}+\mathrm{d}^{*}$ Culture $+\mathrm{e}^{*}$ Female $+\mathrm{f}^{*}$ Ethnic $+\mathrm{g} * \mathrm{X}$. Model $\mathrm{C}$ then distinguishes between presenting the team and individual sports as on a recreational or competitive level. *,**, and $* * *$ denote the 10,5 and 1 percent significance level, respectively. Reported standard errors (in brackets) are adjusted for clustering on the job. 
Table 6. The return to sports for different subgroups. Marginal effects (percentage points).

\begin{tabular}{|c|c|c|c|c|c|c|c|c|}
\hline \multirow[b]{2}{*}{ Variable } & \multicolumn{2}{|c|}{ Native males } & \multicolumn{2}{|c|}{ Native females } & \multicolumn{2}{|c|}{ Ethnic minority males } & \multicolumn{2}{|c|}{ Males (ethnic+minority) } \\
\hline & A & $B$ & A & $\mathrm{B}$ & A & B & $A$ & B \\
\hline \multicolumn{9}{|l|}{ By team and individual sports: } \\
\hline Team sports & $\begin{array}{l}-0.014 \\
{[0.026]}\end{array}$ & - & $\begin{array}{c}0.025 \\
{[0.026]}\end{array}$ & - & $\begin{array}{c}0.028 \\
{[0.024]}\end{array}$ & - & $\begin{array}{c}0.008 \\
{[0.018]}\end{array}$ & - \\
\hline Individual sports & $\begin{array}{c}0.034 \\
{[0.023]}\end{array}$ & - & $\begin{array}{c}0.003 \\
{[0.023]}\end{array}$ & - & $\begin{array}{c}0.031 \\
{[0.020]}\end{array}$ & - & $\begin{array}{l}0.032^{\star *} \\
{[0.015]}\end{array}$ & - \\
\hline By sports: & & & & & - & & & \\
\hline Soccer & - & $\begin{array}{c}0.019 \\
{[0.032]}\end{array}$ & - & $\begin{array}{c}0.036 \\
{[0.033]}\end{array}$ & - & $\begin{array}{c}0.044 \\
{[0.030]}\end{array}$ & - & $\begin{array}{c}0.032 \\
{[0.022]}\end{array}$ \\
\hline Basketball & - & $\begin{array}{l}-0.049 \\
{[0.031]}\end{array}$ & - & $\begin{array}{c}0.014 \\
{[0.032]}\end{array}$ & - & $\begin{array}{c}0.013 \\
{[0.028]}\end{array}$ & - & $\begin{array}{c}-0.017 \\
{[0.020]}\end{array}$ \\
\hline Jogging/running & - & $\begin{array}{c}0.032 \\
{[0.033]}\end{array}$ & - & $\begin{array}{l}-0.003 \\
{[0.032]}\end{array}$ & - & $\begin{array}{c}0.043 \\
{[0.030]}\end{array}$ & - & $\begin{array}{l}0.038^{*} \\
{[0.022]}\end{array}$ \\
\hline Swimming & - & $\begin{array}{l}-0.014 \\
{[0.032]}\end{array}$ & - & $\begin{array}{l}-0.026 \\
{[0.032]}\end{array}$ & - & $\begin{array}{c}0.029 \\
{[0.029]}\end{array}$ & - & $\begin{array}{c}0.007 \\
{[0.021]}\end{array}$ \\
\hline Golf & - & $\begin{array}{l}0.060^{*} \\
{[0.033]}\end{array}$ & - & $\begin{array}{c}0.029 \\
{[0.033]}\end{array}$ & - & $\begin{array}{c}0.036 \\
{[0.030]}\end{array}$ & - & $\begin{array}{l}0.048^{\star *} \\
{[0.022]}\end{array}$ \\
\hline Tennis & - & $\begin{array}{c}0.059^{*} \\
{[0.033]}\end{array}$ & - & $\begin{array}{c}0.010 \\
{[0.034]}\end{array}$ & & $\begin{array}{c}0.017 \\
{[0.029]}\end{array}$ & - & $\begin{array}{c}0.038^{*} \\
{[0.023]}\end{array}$ \\
\hline Other returns: & & & & & & & & \\
\hline Return to work experience & $\begin{array}{c}0.004 \\
{[0.008]}\end{array}$ & $\begin{array}{c}0.004 \\
{[0.008]}\end{array}$ & $\begin{array}{l}0.015^{* *} \\
{[0.008]}\end{array}$ & $\begin{array}{l}0.015^{* *} \\
{[0.008]}\end{array}$ & $\begin{array}{l}0.011^{*} \\
{[0.006]}\end{array}$ & $\begin{array}{l}0.011^{*} \\
{[0.006]}\end{array}$ & $\begin{array}{c}0.008 \\
{[0.005]}\end{array}$ & $\begin{array}{c}0.008 \\
{[0.005]}\end{array}$ \\
\hline Return to cultural activities & $\begin{array}{c}0.041 \\
{[0.029]}\end{array}$ & $\begin{array}{c}0.041 \\
{[0.029]}\end{array}$ & $\begin{array}{l}-0.014 \\
{[0.028]}\end{array}$ & $\begin{array}{l}-0.014 \\
{[0.028]}\end{array}$ & $\begin{array}{l}-0.013 \\
{[0.023]}\end{array}$ & $\begin{array}{l}-0.013 \\
{[0.023]}\end{array}$ & $\begin{array}{c}0.014 \\
{[0.018]}\end{array}$ & $\begin{array}{c}0.014 \\
{[0.018]}\end{array}$ \\
\hline
\end{tabular}

Notes: This table reports marginal effects for the probability of being invited for an interview based on probit regressions for each group of native males and females, ethnic minority males, and then both male groups merged together. Model A divides sports into team and individual sports, while Model B includes an indicator variable for each sport, and in addition controls for cultural activities, work experience, and the full vector $\mathrm{X}$ including all attributes discussed in Section 3.2 using the model Prob (Callback=1) $=\mathrm{a}+\mathrm{b} *$ Sports $+\mathrm{c} * \operatorname{Exp}+\mathrm{d} *$ Culture $+\mathrm{g} * X$. The model used when both male groups are merged also control for ethnicity. *, **, and $* * *$ denote the 10, 5 and 1 percent significance level, respectively. Reported standard errors (in brackets) are adjusted for clustering on the job. 


\section{Appendix A}

Table A1. Descriptives of the population divided at physical fitness below and above the mean (4.29). Men 28-38 years old, 2003. Total population of men.

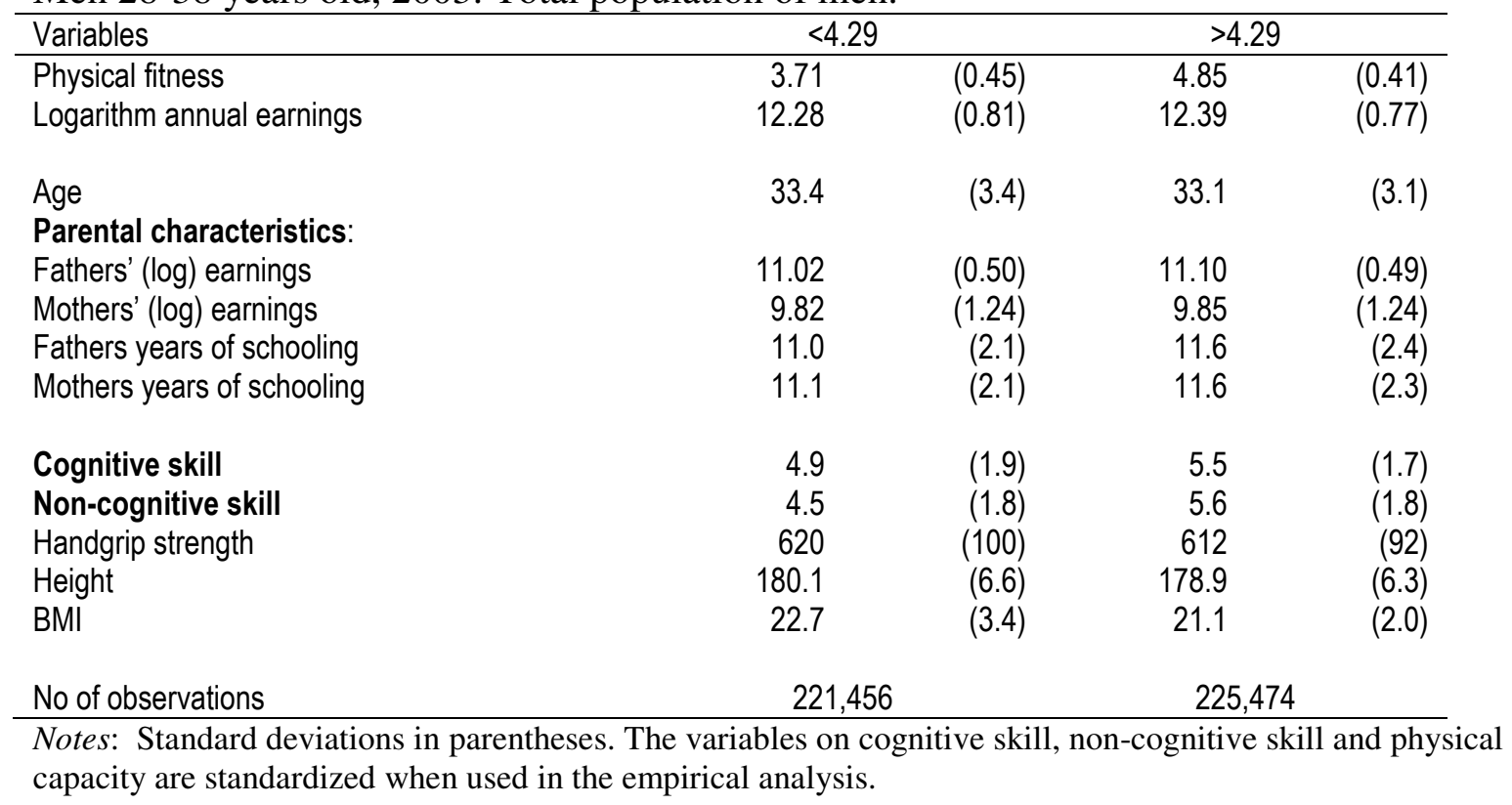


Table A2. The physical fitness premium. Men 28-38 years old, 2003. Logarithm of annual earnings. Total population of men.

\begin{tabular}{|c|c|c|c|c|c|c|}
\hline Outcome and controls & A & $\mathrm{B}$ & C & $\mathrm{D}$ & $E$ & $\mathrm{~F}$ \\
\hline \multicolumn{7}{|l|}{ Log Earnings: } \\
\hline \multirow[t]{2}{*}{ Physical fitness $\left(W_{\max } / \mathrm{kg}\right)$ : } & $0.074^{* * *}$ & $0.063^{* * *}$ & $0.074^{* * *}$ & $0.049^{* * *}$ & $0.017^{* * *}$ & $0.018^{* * *}$ \\
\hline & $(0.001)$ & $(0.001)$ & $(0.001)$ & $(0.001)$ & $(0.001)$ & $(0.001)$ \\
\hline R2 & 0.02 & 0.03 & 0.04 & 0.05 & 0.05 & 0.06 \\
\hline \multicolumn{7}{|l|}{ Years of schooling: } \\
\hline \multirow[t]{2}{*}{ Physical fitness $\left(W_{\max } / \mathrm{kg}\right)$ : } & $0.507^{* * *}$ & $0.360^{* * *}$ & $0.401^{* * *}$ & $0.234^{* * *}$ & $0.198^{* * *}$ & $0.180^{* * *}$ \\
\hline & $(0.003)$ & $(0.003)$ & $(0.003)$ & $(0.003)$ & $(0.003)$ & $(0.003)$ \\
\hline R2 & 0.07 & 0.23 & 0.24 & 0.40 & 0.27 & 0.40 \\
\hline \multicolumn{7}{|l|}{ Controls for: } \\
\hline Parental income and schooling & - & yes & yes & yes & yes & yes \\
\hline BMI and height: & - & - & yes & - & - & yes \\
\hline Cognitive skill: & - & - & - & yes & - & yes \\
\hline Non-cognitive skill: & - & - & - & - & yes & yes \\
\hline No of cases & 446,930 & 446,930 & 446,930 & 446,930 & 446,930 & 446,930 \\
\hline
\end{tabular}

Notes: This table reports estimates from the (1) regression model: Log Earnings $=\mathrm{a}+\mathrm{b} *$ Physical fitness $+\mathrm{c} * \mathrm{X}+\mathrm{f}+$ e. Model A only includes physical fitness and age fixed effects and is estimated using OLS for the total data. Model B adds parental characteristics. Model C adds height and BMI to Model B, while Model D and E adds cognitive skill and non-cognitive skill, respectively, to Model B. Model F includes all variables. 
Table A3. The physical strength premium. Men 28-38 years old, 2003. Logarithm of annual earnings. Siblings data.

\begin{tabular}{|c|c|c|c|c|c|c|c|c|}
\hline Outcome and controls & A & B & $\mathrm{C}$ & $\mathrm{D}$ & $E$ & $\mathrm{~F}$ & G & $\mathrm{H}$ \\
\hline \multicolumn{9}{|l|}{ Log Earnings: } \\
\hline Handgrip strength: & $\begin{array}{c}0.033^{* * *} \\
(0.001) \\
0.01\end{array}$ & $\begin{array}{c}0.032^{\star * *} \\
(0.002) \\
0.01\end{array}$ & $\begin{array}{c}0.035^{* * *} \\
(0.002) \\
0.03\end{array}$ & $\begin{array}{c}0.028^{\star * *} \\
(0.003) \\
0.01\end{array}$ & $\begin{array}{c}0.024^{* * *} \\
(0.003) \\
0.02\end{array}$ & $\begin{array}{c}0.024^{* * *} \\
(0.003) \\
0.04\end{array}$ & $\begin{array}{c}0.015^{\star * *} \\
(0.003) \\
0.04\end{array}$ & $\begin{array}{c}0.013^{* * *} \\
(0.003) \\
0.05\end{array}$ \\
\hline \multicolumn{9}{|l|}{ Years of schooling: } \\
\hline Handgrip strength: & $\begin{array}{c}-0.136^{* * *} \\
(0.003) \\
0.02\end{array}$ & $\begin{array}{c}-0.135^{* * *} \\
(0.005) \\
0.01\end{array}$ & $\begin{array}{c}-0.105^{\text {** }} \\
(0.005) \\
0.22\end{array}$ & $\begin{array}{c}-0.064^{* * *} \\
(0.007) \\
0.01\end{array}$ & $\begin{array}{c}-0.093^{\star \star *} \\
(0.007) \\
0.04\end{array}$ & $\begin{array}{c}-0.100^{\star \star *} \\
(0.006) \\
0.34\end{array}$ & $\begin{array}{c}-0.117^{\star \star \star} \\
(0.007) \\
0.15\end{array}$ & $\begin{array}{c}-0.138^{\star \star *} \\
(0.007) \\
0.36\end{array}$ \\
\hline \multicolumn{8}{|l|}{ Controls for: } & \\
\hline BMI and height: & - & - & - & - & yes & - & - & yes \\
\hline Cognitive skill: & - & - & - & - & - & yes & - & yes \\
\hline Non-cognitive skill: & - & - & - & - & - & - & yes & yes \\
\hline Sibling fixed effect & no & no & no & yes & yes & yes & yes & yes \\
\hline No of cases & 446,930 & 144,671 & 144,671 & 144,671 & 144,671 & 144,671 & 144,671 & 144,671 \\
\hline
\end{tabular}

Notes: This table reports estimates from the (1) regression model: Log Earnings $=\mathrm{a}+\mathrm{b} *$ Sports $+\mathrm{c} * \mathrm{X}+\mathrm{f}+\mathrm{e}$. Model A only includes handgrip strength and age fixed effects and is estimated using OLS for the total data. Model B restricts the data to siblings estimating the same model as in Model A, while model C also adds parental characteristics. Model D include only sibling fixed effects. Model E adds height and BMI, while Model $\mathrm{F}$ adds cognitive skill, Model $\mathrm{G}$ adds non-cognitive skill, and Model $\mathrm{H}$ includes all variables. 
Table A4. Correlation matrix of the included variables in the experiment and their means. 8,500 observations.

\begin{tabular}{|c|c|c|c|c|c|c|c|c|c|c|c|c|c|c|c|}
\hline Variables & Mean & 2. & 3. & 4. & 5. & 6. & 7. & 8. & 9. & 10. & 11. & 12. & 13. & 14. & 15. \\
\hline 1. Callback for interview (0/1) & .25 & .018 & -.010 & .036 & .028 & -.005 & .024 & .001 & -.002 & -.015 & .038 & -.013 & .025 & .024 & .028 \\
\hline 2. Sports $(0 / 1)$ & .62 & - & -.581 & -.002 & .003 & .005 & -.003 & -.005 & .014 & .003 & -.003 & -.003 & -.005 & .008 & .013 \\
\hline 3. Cultural activity $(0 / 1)$ & .17 & & - & -.006 & -.019 & -.004 & -.011 & -.018 & -.007 & -.005 & .003 & .029 & -.008 & .006 & .008 \\
\hline 4. Experience (1-5) & 3.0 & & & - & .532 & -.035 & .317 & .004 & .006 & -.001 & .001 & .012 & .001 & .009 & .003 \\
\hline 5. Number of employers $(0 / 1)^{1)}$ & .45 & & & & - & -.008 & .602 & -.010 & .018 & -.007 & .013 & .004 & -.001 & -.003 & -.004 \\
\hline 6. Unemployed after school $(0 / 1)$ & .20 & & & & & - & -.012 & -.005 & -.009 & .013 & .003 & .002 & -.008 & -.011 & .008 \\
\hline 7. Unemployed in between jobs $(0 / 1)^{2)}$ & .23 & & & & & & - & -.014 & .006 & .012 & .035 & .004 & .001 & .013 & .001 \\
\hline 8. Contemporary unemployed 3 ) & .50 & & & & & & & - & -.010 & .002 & .017 & .006 & .009 & -.007 & .002 \\
\hline 9. Overeducated $(0 / 1)$ & .24 & & & & & & & & - & .006 & .002 & .016 & .000 & .000 & -.002 \\
\hline 10. Job when in school $(0 / 1)$ & .40 & & & & & & & & & - & -.013 & -.006 & -.009 & .000 & .019 \\
\hline 11. US high school $(0 / 1)$ & .07 & & & & & & & & & & - & .012 & .001 & -.002 & -.001 \\
\hline 12. Bad neighborhood (0/1) & .19 & & & & & & & & & & & - & -.246 & .013 & -.005 \\
\hline 13. Good neighborhood (0/1) & .20 & & & & & & & & & & & & - & .033 & -.016 \\
\hline 14. Agreeableness (0/1) & .50 & & & & & & & & & & & & & - & -.016 \\
\hline 15. Extroversion $(0 / 1)$ & .49 & & & & & & & & & & & & & & - \\
\hline
\end{tabular}

Notes:

${ }^{1)}$ Number of employers is either one (0) or three (1) and if three, experience varies between 3 to 5 years. Hence, experience and number of employers are correlated by design.

2) Since one can only be unemployed in between jobs, this variable only varies among those having three previous employments.

${ }^{3)}$ In the analysis contemporary unemployment is divided further into three dummies measuring being unemployed for 3,6 and 9 months. 


\section{Appendix B. The text signaling sports and cultural activities.}

\section{Reference/no sports:}

"I really enjoy my leisure time on evenings and weekends. Since we like to cook, and to have nice evenings at home, we often invite friends over for dinner."

\section{Cultural activities:}

"In my spare time I like to engage in cultural activities. I regularly visit theatres and cinemas, but also musicals and art exhibitions when available."

Team sports (first two signal on recreational level and the other two at a competitive):

"Regarding my other interests I like to engage in recreational sport activities in order to stay in shape. For instance, during the summer season I play soccer in Korpen."

"Regarding my other interests I like to engage in recreational sport activities in order to stay in shape. For instance, during the winter season I play basketball in Korpen."

"I spend quite a lot of time on physical activities when I don't work. Today I play in a lower soccer league than I used to, but it still involves training and matches several times a week."

"I have always been active at a high level of sports, foremost in basketball, in which I played in the elite league. Today I still train regularly and play basketball in a lower level league."

Individual sports (the first four signal on recreational level and the other at a competitive):

"I also like to go jogging. It is important for me to keep my body in shape by exercising regularly."

"I think it is important to stay in shape. Therefore I swim on a recreational basis a couple of times a week. It gives me a relaxing and comforting feeling."

"One of my interests is to play golf. I do not take it too seriously but rather view it as a nice activity and a way to keep my body in shape."

"In my leisure time I like to play tennis. It is a nice way of socializing and an excellent activity for maintaining a good health."

"Even if I have dropped my career as a runner, I still race once in a while. It can be in races as Stockholm Marathon, the Gothenburg circuit or at some local race. Of course, it still requires regular training." 
"I used to be a competitive (elite) swimmer and swimming still involves a large part of my spare time. However, in recent years I don't take it as seriously, but I still compete once in a while."

"Golf is my favorite leisure activity. As often as the weather permits I am at the golf course with my wife or friends. I participate in golf competitions a little bit of everywhere in Sweden and I am the kind of person that really likes the competitive element."

"Tennis has always been an important part of my family and it has certainly shaped my childhood with lots of training and competitions. Even if I do not take it as serious any longer I am still part of a club and train regularly. However, the competitive element is no longer that important." 
Appendix C. Application exemplar: Computer specialists

(own translations into English from Swedish)

$\mathrm{Hi}$,

My name is Karl Johansson and I am 30 years old. I live in Stockholm together with my girlfriend Anna. Previously I worked as a system designer at Telenor AB between 2003 and 2006 in an environment based on win2000/SQL Server. I then participated in three different projects and my work contained development, maintenance and every day problem solving. Development work was done in ASP, C++ and Visual Basic and we used the development platform .Net and MS SQL. In addition I have experience in HTML, XML, J2EE and JavaScript.

I enjoy working with development and problem solving. And I now hope that I will develop further at your company. To my personal characteristics one could add that I find it easy to work both on my own and in a group. I am a dynamic person that likes challenges. I really like my occupation which I think is mirrored in the work I do. I have a degree in computer engineering. I graduated with good grades from Stockholm university.

I also like to go jogging. It is important for me to keep my body in shape by exercising regularly. Me and Anna also like to socialize with our friends during weekends.

I look forward to being invited for interview and I will then bring my good certificates and diplomas.

Best regards

Karl Johansson 